\title{
Team adaptability and task cohesion as resources to the nonlinear dynamics of workload and sickness absenteeism in firefighter teams
}

Article

Accepted Version

Marques-Quinteiro, P., Santos, C., Costa, P., Graca, A., Maroco, J. and Rico, R. (2020) Team adaptability and task cohesion as resources to the nonlinear dynamics of workload and sickness absenteeism in firefighter teams. European Journal of Work and Organizational Psychology, 29 (4). pp. 525-540. ISSN 1464-0643 doi:

https://doi.org/10.1080/1359432X.2019.1691646 Available at https://centaur.reading.ac.uk/83150/

It is advisable to refer to the publisher's version if you intend to cite from the work. See Guidance on citing.

Published version at: https://www.tandfonline.com/doi/full/10.1080/1359432X.2019.1691646

To link to this article DOI: http://dx.doi.org/10.1080/1359432X.2019.1691646

Publisher: Taylor \& Francis

All outputs in CentAUR are protected by Intellectual Property Rights law, including copyright law. Copyright and IPR is retained by the creators or other copyright holders. Terms and conditions for use of this material are defined in the End User Agreement. 


\section{www.reading.ac.uk/centaur}

\section{CentAUR}

Central Archive at the University of Reading

Reading's research outputs online 
Running head: NONLINEAR DYNAMICS IN FIREFIGHTER TEAMS

\section{Team adaptability and task cohesion as resources to the nonlinear dynamics of workload and sickness absenteeism in firefighter teams}

Pedro Marques-Quinteiro ${ }^{1}$, Catarina Marques dos Santos $^{2}$, Patrícia Costa ${ }^{3}$, Ana Margarida Graça ${ }^{4}$, João Marôco ${ }^{1}$, Ramón Rico ${ }^{5}$

${ }^{1}$ Postal address: Rua Jardim do Tabaco, $\mathrm{n}^{\circ} 34$. 1149-041 Lisboa.

${ }^{1}$ Department: William James Center for Research, ISPA, Instituto Universitário, Lisboa, Portugal.

${ }^{2}$ Postal address: Maastricht University, School of Business and Economics, P.O. Box 616, 6200 MD Maastricht, The Netherlands.

${ }^{2}$ Department: Organization, Strategy, and Entrepreneurship.

${ }^{3}$ Postal address: ISCTE- Instituto Universitário de Lisboa, Avenida das Forças Armadas, 1649-026, Lisboa, Portugal.

${ }^{3}$ Department: Human Resources and Organizational Behavior, Lisboa, Portugal.

${ }^{4}$ Postal address: Henley Business School at The University of Reading Greenlands Campus, Henley on Thames, Oxfordshire, United Kingdom. RG9 3AU.

${ }^{4}$ Department:Henley Centre for Leadership; Leadership, Organisations and Behaviour

${ }^{5}$ Postal address: Business School, The University of Western Australia, 35 Stirling Hwy, Perth WA 6009, Australia.

${ }^{5}$ Department: Business School, the University of Western Australia, Perth, Australia.

Word count: 12812

Authors' notes regarding funding. William James Center for Research, ISPA Instituto Universitário is financed by FCT (ref. UID/PSI/04810/2019). The current study was partially supported by one individual postdoctoral grant by the FCT Grant No.

SFRH/BPD/114934/2016.

Acknowledgements: The authors would like to thank to the action editor and the reviewers for their constructive feedback, which was very helpful in the development of this manuscript. The authors would also like to thank to the Lisbon City Hall - Fire Brigade Department, for having agreed with this project. Finally, we would also like to thank to the Firefighting men and women that give their best, every day, exchanging one life for another. 


\section{Team adaptability and task cohesion as resources to the nonlinear dynamics of workload and sickness absenteeism in firefighter teams}

The current study builds on the Nonlinear Dynamic Systems (NDS) perspective to test the assumption that change in sickness absenteeism is nonlinear, and that such change is due to workload, team adaptability and task cohesion. Participants were 37 firefighter teams $(n=250$ individuals) from a main European capital city. The research hypotheses were tested using SPSS and the "cusp" package, in the statistical software R. The results suggest that change in sickness absenteeism behaviours over time is nonlinear, with the cusp catastrophe model predicting such behaviours better than the linear and logistic models. In our model, task cohesion functions as an asymmetry factor (i.e. the independent variable that determines the strength and discrepancy between the two stable states of the dependent variable) leading to linear change in sickness absenteeism. Interestingly, both workload and team adaptability function as bifurcation (i.e. the independent variable that determines the change between the two stable states of the order parameter) and asymmetry factors leading to nonlinear and linear change in sickness absenteeism over time. This study contributes to the growing evidence that incorporating the NDS perspective enables a better understanding of action teams, namely those working in extreme environments.

Keywords: complex adaptive systems; nonlinear dynamic systems; team adaptability; task cohesion; sickness absenteeism 


\section{Introduction}

On 14 June 2017, the Grenfell Tower fire broke in North Kensington, West London, United Kingdom. Over 48 hours, 250 firefighters fought to contain the blaze and rescue nearly 300 victims trapped inside the burning building. Despite their efforts, 72 civilians died, and 70 others were wounded in the largest fire in the United Kingdom since World War II (The Guardian, 2018).

Firefighters face unique demands that can be highly related to the risk of severe physical and psychological trauma (Ângelo \& Chambel, 2013). The dangers of the firefighting activity increase when professionals face chronic job demands that raise the probability of sickness absenteeism (i.e. the voluntary and involuntary sickness absence behaviour of individuals in the workplace - Schaufeli, Bakker, \& Van Rhenen, 2009). Sickness absenteeism is a bimodal behaviour in the sense that it only includes two stable behavioural states: being (sick) absent from work vs. not being (sick) absent from work (Schaufeli et al., 2009).

For firefighters, sickness absenteeism means fewer personnel available responding to distress calls and emergencies. Furthermore, sickness absenteeism is also problematic because it may flag chronic job demands that negatively influence well-being and create serious staffrelated financial expenses (Szubert \& Sobala, 2002). Still, whereas it is beyond doubt that sickness absenteeism is troublesome, research efforts aiming to prevent or mitigate its occurrence remain limited (Schaufeli et al., 2009). Despite the prevalence of sickness absenteeism in high demanding occupations such as firefighting or healthcare, meta-analytical findings are unclear about which factors enable or mitigate sickness absenteeism (Darr \& Johns, 2008; Kuoppala, Lamminpää, \& Husman, 2008). Such fuzziness is also visible in longitudinal studies reporting distinct trajectories of sickness absenteeism over time. One example regards research by Ferguson (1972), which shows that employees' proneness to engage in multiple sickness absenteeism episodes over time follows a binomial negative 
distribution (i.e., discrete probability distribution of the number of successes in a sequence of independent and identically distributed Bernoulli trials before a non-random number of failures occurs - DeGroot, 1986). Another example regards research by Hausknecht, Hiller and Vance (2008) showing that change in sickness absenteeism follows a linear trend and that this trend is related with Unit-level satisfaction and commitment.

The diversity of research findings, alongside the bimodality of sickness absenteeism, suggests that nonlinear properties such as hysteresis, i.e. any sudden transition between at least two stable states of a system (Guastello, 2011), may better characterize sickness absenteeism. If that is correct, then traditional statistical approaches grounded on the general linear model might not capture absenteeism adequately (Guastello, 2001; Ramos-Villagrasa, MarquesQuinteiro, Navarro, \& Rico, 2018). We address these limitations on research and expand current knowledge on the nonlinear dynamics of sickness absenteeism by building on the Job Demands-Resources (JD-R) model (Bakker \& Demerouti, 2017), the theory of teams as complex adaptive systems (tCAS; Arrow, McGrath, \& Berdahl, 2000), and the team adaptation literature (Maynard, Kennedy, \& Sommer, 2015a), integrating those within the Nonlinear Dynamic Systems (NDS) perspective (Guastello \& Liebovitch, 2009).

The JD-R model proposes dual pathways for the two types of job characteristics it defines: job demands and job resources (Demerouti, Bakker, Nachreiner, \& Schaufeli, 2001). While job demands are contextual elements forcing individuals to exert continued physical and/or psychological effort for prolonged periods, job resources are the variables that are instrumental in attaining work goals and buffer job demands (Bakker \& Demerouti, 2017). The JD-R model also suggests job demands have less negative influence on well-being and performance when individuals have the psychological and social resources they need to perform (Demerouti et al., 2001). Following previous research that has investigated job resources at the team level (Costa, Passos, \& Bakker, 2015; Ellis \& Pearsall, 2011), in this 
study we posit the JD-R model as an isomorphic model in the sense that its properties can apply to both the individual and the team level of analysis (Costa, Passos, \& Bakker, 2014; Urien, Rico, Demerouti, \& Bakker, 2017). We do so by proposing workload as a team-level demand, and team adaptability and task cohesion as two team-level resources that are key for teams performing under extreme task conditions (Burke, Stagl, Salas, Pierce, \& Kendall, 2006; Christian, Christian, Pearsall, \& Long, 2017; Guastello et al., 2013; Maynard, Kennedy, Sommer, \& Passos, 2015b). In this study we regard workload as the amount of psychological and physical load exerted on individuals and collectives (Bakker, Demerouti, Boer, \& Schaufeli, 2003), team adaptability as the capacity of a team to make necessary changes in response to a disruption or trigger (Maynard et al., 2015a), and task cohesion as the tendency for a team to stick together and remain united in its pursuit of instrumental objectives (Carless \& De Paola, 2000).

Different from team adaptive performance or team adaptive efficacy (e.g. LePine, 2005; Marques-Quinteiro, Curral, Passos, \& Lewis, 2013), we still know very little regarding the extent to which team adaptability has a positive impact on teamwork dynamics (Burke et al., 2006; Maynard et al., 2015a). Team adaptability is a main antecedent of team adaptation. It is a relatively stable team characteristic, resulting from the combination of team members' experience with tasks requiring adaptation, plus the external resources to which team members have access to assist them in their work (e.g. tools, vehicles, time-Maynard et al., 2015a). The theory of tCAS, alongside prevailing teamwork theories, generally suggests that team adaptability enables team adaptation processes and effectiveness in complex and extreme work environments (e.g. Burke et al., 2006; Christian et al., 2017). This is particularly true for action teams, where the capacity to change behaviours, affect and cognitions in response to unexpected events is fundamental for mission success (Devine, 2002). 
Besides adaptability, for action teams, such as firefighter teams, having a stable social structure to ensure the connectedness between team members is necessary to allow these teams to perform regardless of the working environment conditions (e.g. Kozlowski \& Chao, 2012; Maynard et al., 2015b). Such connectedness is achieved through task cohesion, which is a relatively stable team characteristic that enables team processes and outcomes (e.g. Beal, Cohen, Burke, \& McLendon, 2003), as well as the stability of teams over time (Kozlowski, Gully, Salas, \& Cannon-Bowers, 1996). Moreover, while cohesion is a good thing for the performance of teams that work under great stress (e.g. Zaccaro, Gualtieri, \& Minionis, 1995), studies examining the relationship between task cohesion and teamwork outcomes in extreme professional occupations such as firefighting are scant. We address both lacunas since the lack of empirical studies that support theoretical assumptions weakens scientific knowledge.

In light of the aforementioned rationale, the goal of the current research is to test the general hypothesis that team job demands (i.e. workload) and team job resources (i.e. team adaptability and task cohesion) shape the nonlinear dynamics of sickness absenteeism. Hence, the contribution of this study to team literature is threefold. First, it contributes to the tCAS theory by examining the nonlinear dynamics of change for sickness absenteeism from a NDS perspective. In so doing, we incorporate the idea of emergence and nonlinear change in the dynamics of phenomena. Accordingly, we combine the JD-R model with tCAS theory and recent models of team adaptation within the NDS perspective to better understand the nonlinear dynamics of sickness absenteeism in the workplace. This answers previous calls for the incorporation of tCAS in teamwork research and carrying out team adaptation research under a temporal logic (e.g. Kennedy \& Maynard, 2017; Ramos-Villagrasa et al., 2018). Second, it contributes to the exploration of the JD-R model at the team level as we propose team adaptability and task cohesion as team resources that reduce the role of team job demands over time. Finally, this study contributes to our knowledge about action teams and teams in extreme 
environments as we empirically examine the conditions that enable firefighters in ameliorating and preventing the occurrence of sickness absenteeism behaviours (Maynard, Kennedy, \& Resick, 2018).

\section{Theoretical background}

\section{The NDS theory and teams as complex adaptive systems}

Nonlinear dynamic systems (NDS) theory, or chaos theory, is the study of complex systems (Guastello \& Liebovitch, 2009). Complexity regards phenomena that although might seem random or too complicated to be made sense of, are actually deterministic in the sense that there is sensitivity to initial conditions (i.e. small changes in a system's characteristics causing dramatic change later on). The NDS theory offers an array of methodologies to study phenomena that often happens far from equilibria, and that can be easily mistaken as error variance when linear methods are used. Indeed, while linear methods assume that all change is smooth or incremental, and are blind to discontinuities and bifurcations, methodologies derived from NDS theory are specifically designed to capture such discontinuities and even predict under which conditions they are likelier to happen (Guastello \& Liebovitch, 2009).

One contribution that has set the stage for the integration of the NDS theory within the work and organizational psychology literature was Arrow et al. (2000) theory of tCAS. Within this theory, small groups such as firefighter teams are complex systems that interact with smaller systems (i.e. team members) embedded in the larger organizational system (e.g. the multi-team system composing one firefighter station). The tCAS also allows us to characterize teams as open systems, whose temporal evolution is dependent on causal dynamics that systematically and nonlinearly shape team functioning over time. According to Arrow et al., there are three causal dynamics in teams: local dynamics, global dynamics, and contextual dynamics. Local dynamics describe the behaviour, cognition and motivation of team members in interaction with their environment. Examples of team local dynamics can be the individual 
situation awareness or the flow experience of each team member during task performance. At the dyad-team level of causality, there are global dynamics that describe the collective processes and emergent structures that unfold as team members coordinate to accomplish common goals and develop shared cognitions (e.g. team situation models). Finally, contextual dynamics regard the impact of context-specific features on teams' local and global dynamics, such as task complexity or external feedback.

According to Kozlowski et al. (1996) and Arrow et al. (2000), the complexity of teams emerges from such factors as technological jumps, unpredictability, and the interdependence of teamwork itself; whereas being an adaptive system means that teamwork dynamics have iterative and chaotic properties like teams' long term behaviour (e.g. coordination) being sensitive to team initial conditions (e.g. team composition). Different authors have reasoned in favour of using the NDS perspective to expand what we know and how we think about teamwork (e.g. Arrow et al., 2000; Guastello \& Guastello, 1998; Kozlowski, Chao, Grand, Braun, \& Kuljanin, 2016; Ramos-Villagrasa et al., 2018). This reasoning is supported by growing evidence of the existence of a positive relationship between chaotic dynamics and team performance, processes, and leadership (e.g., Boos, Pritz, Lange, \& Beltz, 2014; Contractor, DeChurch, Carson, Carter, \& Keegan, 2012; Curral, Marques-Quinteiro, Gomes, \& Lind, 2016; Gorman, Cooke, \& Amazeen, 2010; Ramos-Villagrasa, Navarro, \& GarciaIzquierdo, 2012).

Despite the sound contribution of the work of Arrow et al. (2000) to the teamwork literature, and the general acknowledgement that teams are complex systems (e.g. Mathieu, Gallagher, Domingo, \& Klock, 2019), the number of empirical contributions that theoretically and empirically incorporate tCAS remains modest (Ramos-Villagrasa et al., 2018). Following Guastello (2001) and Ramos-Villagrasa et al. (2018), three arguments that justify this disconnection between theory and research are that hundreds of data points are needed to 
extract chaotic patterns; taking a NDS perspective entails the need to apply sophisticated methods such as the estimation of maximum Lyapunov exponents, recurrence plots, and surrogate data; and the mathematics are too demanding.

Interestingly, within the vast array of empirical tools that fall within the NDS theory, some are far simpler to implement than sophisticated linear approaches such as random coefficient modelling (Bliese \& Ployhart, 2002). One example of such a straightforward approach is cusp catastrophe modelling (Guastello, 2011). Cusp catastrophe theory (Zeeman, 1979) offers mathematical capabilities that are suited to examine chaotic behaviour in cases with at least one time point, and where chaos in one dependent variable can be explained by two independent variables (Guastello, 2011). We argue that, as cusp catastrophe theory has been successfully applied to the study of individuals in the workplace (e.g. Ceja \& Navarro, 2012; Guastello et al., 2012; Sheridan, 1985), so can it be used to truly address the complexity of teamwork (e.g. Dimas et al., 2019; Guastello, Correro II, \& Marra, 2019; Rebelo et al., 2016).

\section{A cusp catastrophe model of sickness absenteeism in firefighters}

Catastrophe theory (Zeeman, 1979) applies mathematical models of nonlinear dynamics to describe discontinuities in physical, biological, and psychological systems (Guastello, 1991, 2001; Sheridan, 1985; Zeeman, 1979). The core axiom of catastrophe theory is Thom's (1975) classification theorem which states that given a maximum of four control parameters (i.e. independent variables) all discontinues changes can be modelled through several elementary topological forms where cusp catastrophes are included (for a detailed review see Guastello, 2011). Two typical examples of events in work and organizational psychology that would trigger catastrophic behaviour in the order parameter (i.e. dependent variable) would be the deployment of one training intervention between measurement occasions, or a sudden change in work conditions that triggered the need for adaptation (e.g. Guastello \& Guastello, 1998). 
Figure 1 summarize the cusp catastrophe model of sickness absenteeism in firefighter teams.

\section{$<$ Insert Figure 1 here>}

The cusp catastrophe model is very different from a linear model in critical ways. First, while a cusp model allows the simultaneous modelling of back and forward change in the order parameter following different paths (e.g. from B to A, and from D to C, in Figure 1), linear modelling requires that backward progression follows the same path as the forward progression does. Secondly, cusp models cover both the continuous components and the discrete components of change. While continuity is visible through linear and smooth behaviour (paths B to A or A to B, in Figure 1), discrete change is visible by sudden and nonlinear events (paths $\mathrm{D}$ to $\mathrm{C}$ or $\mathrm{C}$ to $\mathrm{D}$, in Figure 1).

A cusp catastrophe is a three-dimensional surface that features a two-dimensional manifold (Guastello, 2011). The cusp describes one order parameter $y$ (dependent variable) that has two stable states and is a function of two control parameters (independent variables): asymmetry $(a)$ and bifurcation $(b)$. The equilibrium plane shown in Figure 1 regards the degree of change in the order parameter $y$ for all possible combinations of the two control parameters, $b$ and $a$. In the two stable (flat) regions of the equilibrium plane (A and $\mathrm{B}$ ), change in the order parameter $y$ is linear. Outside the two stable regions, when approaching the cusp region $(\mathrm{C}$ and D), change in the order parameter $y$ becomes unstable and discontinuities take place. Catastrophic behaviour happens when the values of the order parameter $y$ fall within the cusp region, represented as the grey shaded, V-shaped region at centre of the asymmetry axis. Below, we develop our cusp catastrophe model of sickness absenteeism in firefighters.

A cusp catastrophe model of change in sickness absenteeism behaviours should describe the sudden and discontinuous process through which sickness absenteeism shifts between two stable states: being sick absent vs. not being sick absent. Stability means that once 
in a given stable state, the system will remain in that state until it jumps back to its former stable state. The sickness absenteeism dynamics can be described by the cusp catastrophe equation: $d y / d t=y^{3}-b y-\bar{a}$

Where sickness absenteeism is the order parameter $y$, and two control parameters, $b$ and $a$. The two control parameters divide onto one bifurcation factor $b$ and one asymmetry factor a. While the bifurcation factor determines the change between the two stable states of the order parameter, the asymmetry factor determines the strength and discrepancy between the two stable states of the order parameter. Since cusp catastrophes describe chaotic behaviour, it can happen that for a restricted set of values of the bifurcation factor, very small changes in the asymmetry factor might trigger catastrophic changes in the order parameter. Differently, it can also happen that for other restricted set of bifurcation values, even large changes in the asymmetry factor might not move the order parameter to shift between states. Instead, such changes in the asymmetry factor might lead to gradual and continuous change in the order parameter.

Hence, what will determine how the order parameter oscillates between the two stable states are the values adopted by the bifurcation and the asymmetry factors simultaneously. Following this rationale, in our cusp catastrophe model of change in sickness absenteeism behaviours, the order parameter $y$ is sickness absenteeism, which is a function of the control parameters workload $b$, team adaptability $a_{1}$ and task cohesion $a_{2}$. The order parameter becomes bimodal for given $b, a$ pairs within the cusp region. This means that for a given paired value of $b$ and $a$ within the cusp region, two distinct values of $y$ can occur (being sick absent and not being sick absent, which reflect the bimodality of $y$ ). Outside the bifurcation region, the distribution of the order parameter $y$ becomes continuous, and any given paired values of the control parameters $b$ and $a$ usually produce one response type in the order parameter $y$. In cusp catastrophe models, $a$ is the asymmetry factor because changes in this control parameter 
should trigger proportional changes in the order parameter $y$. This is the linear part of the model where change is smooth and continuous (A and B region, in Figure 1). Differently, the bifurcation factor $b$ regards the level of workload individuals are experiencing and is responsible for the sudden transitions in the stable state of the order parameter, around the cusp region ( $\mathrm{C}$ and $\mathrm{D}$ region, in Figure 1). As an example, when the levels of workload are low and the levels of team adaptability and task cohesion are high, there could be a sudden drop in the number of sickness absenteeism behaviours. Differently, as the levels of workload increase and the levels of team adaptability and task cohesion decrease, there could be a sudden jump in the number of sickness absenteeism behaviours.

\section{Research hypotheses}

Integrating the JD-R model and the tCAS theory within the NDS perspective, in this study, the degree of workload acts as a contextual dynamic that functions as a job demand and a control parameter $(b)$ with bifurcation function. Both team adaptability and task cohesion are global, team-level dynamics that function as team resources and control parameters $\left(a_{1}, a_{2}\right)$ with asymmetry functions.

Traditionally, high workload is perceived as a job demand as it requires sustained effort (whether physical or psychological), therefore consuming energy because the work needs to be completed (Bakker \& Demerouti, 2017). As a job demand, workload is the most important predictor of job absence duration, and a strong predictor of employees' health problems (e.g. Rauhala et al., 2006). In the context of teams, and particularly of action teams, considering that team members experience the same work context and its dynamics, it is easy to conceptualize their shared demands as a team-level construct (Urien, et al., 2017). For example, if team members experience the same level of time pressure and perceive it consensually, their joint perception should reflect the quality/intensity of the demand (Bakker \& Demerouti, 2017). One recently published study by Reuver, Van de Voorde, and Kilroy (2019) suggests that a 
disproportionality exists, since only high levels of workload seem to influence employees' absenteeism behaviours. This means that regardless of the increases or decreases in workload level, it is only under a restricted set of workload values that a sudden change in employees' behaviour can be observed. This suggests that workload should be a bifurcation factor $(b)$ that is responsible for modelling sickness absenteeism transitions between its two stable states.

Team resources will function analogously as the JD-R model proposes, by buffering job demands impact on team member strain (Urien et al., 2017). Team members belonging to teams with high resources (team adaptability and task cohesion, in this study) should be better equipped to deal with the strain caused by increased job demands such as workload, therefore presenting fewer negative and performance consequences (Bakker \& Demerouti, 2017). While team adaptability might render firefighting teams the pool of internal resources they need to adapt to unexpected events that happen during performance (Cohen-Hatton, Butler, \& Honey, 2015; Maynard et al., 2015a; Uitdewilligen, Rico, \& Waller, 2018), task cohesion may help to prevent coordination breakdowns during task performance (Beal et al., 2003; Maynard et al., 2015b). Therefore, both resources potentially enhance workload resilience and reduce the frequency of sickness absenteeism over time, by protecting team members from excessive physical or psychological strain.

For different increasing levels of team adaptability, we expect proportional decreasing levels of sickness absenteeism behaviours, especially in action teams. For instance, at lower levels of team adaptability, sickness absenteeism will be likely to happen since team members will probably need to spend extra time and cognitive resources developing alternative courses of action to deal with an unexpected event. For teams that operate in extreme and complex environments, this must be done in a short period of time and considering multiple, sometimes unpredictable, variables. As a result, the strain these teams experience because of the situation itself (e.g. a multiple car crash with many severely wounded individuals), may be increased by 
adding extra cognitive (e.g. coming up with an action plan) and emotional (e.g. the anxiety of time constraints) demands (Cohen-Hatton et al., 2015; Maynard et al., 2018).

Simultaneously, as the level of team adaptability increases so the number of sickness absenteeism behaviours should decrease. Team adaptability can work as a team resource enhancing successful team adaptation and increasing control over the work environment (Burke et al., 2006; Maynard et al., 2015a). This should help team members cope in workload situations, both in terms of team processes used when firefighting teams perform their missions (e.g. monitoring team members when extinguishing a fire or extricating an individual after a car crash with temporal and personnel constraints) and in terms of mitigating motivational losses and consequent strain gains.

Building on the work of Arrow et al. (2000) and Demerouti et al. (2001), we also theorize that task cohesion is a team resource influencing the nonlinear dynamics of change in sickness absenteeism. We propose that the level of change in task cohesion is proportional to the level of change in sickness absenteeism in such a way that a linear increase in task cohesion leads to a proportional decrease in sickness absenteeism. Higher cohesive teams should have strong social ties and more stable group structures that will render team members a greater perception of support (e.g. Balkundi \& Harrison, 2006). This should reduce team members' willingness to engage in sickness absenteeism behaviours, either because they feel their team members' support or because they do not want to let them down by being absent from work (e.g. Dekkers-Sánchez et al., 2007). The fact that teams have high task cohesion might also be helpful if the team finds some kind of obstacle, because teams that are more cohesive will be less likely to dismantle and fail (Maynard et al., 2015b). Additionally, the members of teams that have high task cohesion will invest more effort in helping each other to achieve team goals, hence being more resilient to job demands and less likely to be absent from work (Kozlowski \& Chao, 2012; Maynard et al., 2015b). 
As the level of task cohesion decreases, teams will present a poor connectedness between team members, which will also be less united in pursuing common goals (Beal et al., 2003; Carless \& De Paola, 2000). As a result, those individuals whose physical or psychological health is weak will more wittingly engage in sickness absenteeism behaviours because they do not perceive a strong support from colleagues, nor feel like they have to be there for the team (e.g. Balkundi \& Harrison, 2006; Kozlowski \& Chao, 2012). The absence of a shared purpose may increase the salience of individual needs for recovery and stop them from engaging in reciprocity behaviours, such as sustaining physical or psychological effort. Furthermore, low task cohesion may increase the probability of coordination breakdowns and conflict emergence when team members face complex and uncertain tasks (e.g. Maynard et al., 2015b). As a result, team members are likely to become emotionally exhausted and engage in sickness absenteeism behaviours as a coping mechanism to recover (Dekkers-Sánchez et al., 2007; Xanthopoulou et al., 2007). Similar to team adaptability, for different levels of workload along the Y-axis of the cusp control plane, increasing levels of task cohesion should therefore be related with decreasing levels of sickness absenteeism. Finally, the body of knowledge on sickness absenteeism is fuzzy in the sense that there seems to be no consensus regarding what promotes or mitigates sickness absenteeism. More, as other catastrophic phenomena such as performance (Guastello et al., 2014), flow (Ceja \& Navarro, 2012), and learning (Rebelo et al., 2016), sickness absenteeism also seems to display bimodality and hysteresis, which are fundamental flags for the existence of catastrophic behaviour (Ceja \& Navarro, 2012; Guastello, 2011). In the introduction of this article, we have operationalized the general hypothesis that change in sickness absenteeism can be described through cusp catastrophe modelling. More, the fuzziness of research findings and the bimodality of sickness absenteeism further substantiate the idea that traditional linear modelling approaches (e.g. GLM) are inadequate to describe the dynamics of change in sickness absenteeism. We hypothesize that: 
Hypothesis 1: The cusp catastrophe model of the relationship between workload, team adaptability, and sickness absenteeism will explain more variance than its comparable linear model.

Hypothesis 2: The cusp catastrophe model of the relationship between workload, task cohesion, and sickness absenteeism will explain more variance than its comparable linear model.

\section{Method}

\section{Participants}

Participants were 250 firefighters, composing 37 firefighting teams responsible for controlling and extinguishing municipal fires, protecting life and property and conducting rescue efforts; thus, being often required to perform under intense and dangerous conditions. Accordingly, our sample were action teams, as firefighter teams are small groups of individuals that come together for short periods to perform tasks that are often challenging and full of contingencies (Sundstrom, 1999). Our firefighting teams sample distributed across three battalions, six companies and ten fire stations in a main European capital. Participants' mean age was 35.74 years $(S D=6.66), 98.3 \%$ were male and $26.3 \%$ had at least the ninth grade of education. Team size ranged between 5 and 26 individuals, with an average team size of 15.48 individuals ( $S D$ =6.29). On average, participants had been in their firefighting department for 13.01 years $(S D$ $=6.45)$, and in their team for 5.06 years $(S D=4.81)$.

\section{Research design}

The current study followed a correlational and longitudinal design, and we have regarded a full year as a complete performance cycle (Marks et al., 2001). January and December were the beginning and ending moments, and July was the midterm moment (Gersick, 1991; Roe, 2008). When collecting longitudinal data, researchers must be mindful about the nature of the research constructs, as well as the timing of data collection (Navarro et al., 2015; Ramos-Villagrasa et 
al., 2018; Roe, 2008). In our case, the goal was to test whether team adaptability and task cohesion as team resources were asymmetry factors to nonlinear change in sickness absenteeism behaviours, while workload was a bifurcation factor. For teams with a long existence, such as the ones in our sample, team adaptability and task cohesion are relatively stable constructs that (a) can be reliably measured by means of psychological scales (e.g. Maynard et al., 2015b), and that (b) can be regarded as being positively related to most team processes and emergent states (e.g. Zaccaro et al., 1995). To account for team adaptability and task cohesion as inputs to teamwork phenomena, these should be measured in either the beginning or the midterm of the team performance cycle (Cronin, Weingart, \& Todorova, 2011; Gersick, 1991; Roe, 2008). Since data collection in January and February was not possible due to practical constraints, the second optimal solution to initiate data collection was in June and July, the halfway transition months of the fire fighters' annual performance cycle.

Regarding sickness absenteeism and workload, these are likely to change over time (e.g. Bakker \& Demerouti, 2017). We decided to gather seven months of raw data from the second half of the fire fighters' annual performance cycle, for two reasons. First, the best way to capture and study change in sickness absenteeism and workload is by means of collecting data on multiple occasions over time (Navarro et al., 2015; Ramos-Villagrasa et al., 2018). Second, change in team characteristics and emergent team phenomena such as team adaptability and task cohesion often happen in the beginning and halfway transition periods of a team performance cycle (Marks et al., 2001). Hence, team adaptability and task cohesion should be factors measured during the halfway transition months to explain change in sickness absenteeism during the second half of the fire fighters' annual performance cycle.

\section{Procedure}

Data collection took place during the second half of 2016. Participants learned about the study in May, through an internal order of service issued by the department's official communication 
channels (e.g. intranet). Between June and July, data on team adaptability and task cohesion was collected once, using paper and pencil questionnaires filled in by participants at fire stations during daytime service.

We asked the Firefighters Department of Human Resource Management (HRM) to provide us with the raw data records from June to December, to determine team-level workload and sickness absenteeism, as we explain below in the measures sub-section. Those records covered the month of the questionnaire application plus the following six months (i.e. June to December). Participation in the study was voluntary. However, the research team gave the firefighters' department two research reports and one workshop summarizing the study main findings, as compensation for collaboration.

\section{Measures}

Team adaptability. This construct was measured using Marques-Quinteiro, RamosVillagrasa, Passos, and Curral's (2015) measure of adaptive performance, where participants were asked to rate their team's general ability to perform adaptively (Maynard et al., 2015a). The measure that was used includes eight items assessing four dimensions: solving problems creatively (e.g. "We engage in creative action to solve problems for which there are no easy or straightforward answers"), dealing with uncertain and unpredictable work situations (e.g. "We adjust and deal with unpredictable situations by shifting focus and taking reasonable action"), learning work tasks, technologies and procedures (e.g. "Periodically, we update technical and interpersonal competences as a way to better perform the tasks in which we are enrolled"), and handling work stress (e.g. "We remain calm and behave positively during highly stressful events"). Participants were asked to share their level of agreement regarding the way their team coped with unexpected events and gave their answers on a 5-point Likert-type scale $(1=I$ totally disagree and $5=$ I totally agree $)$. Cronbach $\alpha=.92$. 
Task cohesion. This construct was assessed using four items from the group environment questionnaire (Carless \& De Paola, 2000). An example of the items is: "My fellow team members and I are united in the performing of our goals". Participants were asked to share their level of agreement regarding team members' task cohesion and gave their answers on a 5-point Likert-type scale $(1=I$ totally disagree, and $5=I$ totally agree $)$. Cronbach $\alpha=.76$.

Workload. Bedwell, Salas, Funke and Knott (2014) suggest that the extent to which workload fluctuates across performance episodes depends on the amount of team workload (i.e. the amount of load resulting from characteristics of the team such as team size or team members' skills), and the amount of task workload (i.e. from the load emerging from task characteristics such as task complexity or task difficulty). Following Cohen-Hatton et al. (2015), the typology of incidents attended by urban fire fighters can differ in the level of risk (high vs. low) and urgency (time available vs. time pressure); and the extent to which (a) specific incidents will happen, and (b) the order by which the incidents will happen is often random. Such randomness convenes a dynamic character to the amount of task workload of urban firefighters. Furthermore, while team members change the response vehicle to which they are assigned at each new work shift, the level of staffing to tackle each incident is stable since it follows standard routine procedures (e.g. an ambulance can carry two to three individuals, while a firefighting urban truck can carry up to 8 individuals). Hence, differently from task workload, such constancy gives a more stable character to the amount of workload of urban firefighters.

In this study, rather than taking a subjective approach to the measurement of workload (e.g. NASA Task Load Index; Hart \& Staveland, 1988), we captured workload objectively. To do so, we combined the ideas of Bedwell et al. (2014) and Cohen-Hatton et al. (2015) operationalizing workload in urban firefighters as the ratio between the number of emergency calls attended per month (a proxy of task workload) divided by the size of the teams available 
to respond to those calls (a proxy of team workload). As an example, imagine that team A and team B both receive 20 emergency calls. Team A has eight members and team B has 15 members. The workload for team A would be 2.5 and the workload for team B would be 1.33. Figure 2 displays the within team trajectories of workload over seven months.

$<$ Insert Figure 2 here>

Sickness absenteeism. This construct was measured as the frequency of sick leaves per team over seven months (counting from the month of the survey data collection), following Hensing, Alexanderson, Allebeck and Bjurulf (1998). The HRM department provided the research team with the exact number of sick leaves per team on a monthly basis. The decision of using frequency of sick leave as a measure of sickness absenteeism was driven by Hensing et al.'s (1998) argument that this measure is based on the whole population, it is simple to assess, it is better suited for small samples (such as ours) and it is easy to interpret. Figure 3 displays the within team trajectories of sickness absenteeism over seven months.

$<$ Insert Figure 3 here>

\section{Statistical analyses}

Cusp catastrophe models can be described using such methods as dynamic difference equations (using polynomials), nonlinear regressions (also known as the direct method; Guastello, 2002), and maximum likelihood estimation (also known as the indirect method; Cobb \& Watson, 1980). Dynamic difference equations allow researchers more flexibility regarding the estimation of change trajectories for time series data, and the comparison between two different time points between which at least one radical event happened in the system that should trigger catastrophic behaviour in the control parameter (e.g. Guastello et al., 2018; Rebelo et al., 2016). However, in cases where the optimal time lag between cases, or the timing of radical shifts in system conditions are unknown (e.g. when an intervention was deployed), nonlinear regression methods offer a more reliable and parsimonious alternative to the estimation of cusp 
catastrophe models. In the current study, we have tested our main hypothesis using the direct method of static nonlinear regressions proposed by Guastello (2002). Specifically, we adopted a static model for the catastrophe function since this particular model performs equally well with data that is collected on one single occasion, or on a small number $(>2)$ of multiple occasions over time (Guastello, 2011). The model fits the data to a probability density function $(p d f)$ that is uniquely associated with the cusp catastrophe model (Guastello, 2014). The data only must be as in a time series format, with each column containing all the observations made for each team, over time. The cusp analysis for sickness absenteeism was the probability density function of the cusp response surface, expressed by the nonlinear regression function described in the equation 2:

$P d f(z)=\xi \exp \left(\theta_{1} z_{1}^{4}+\theta_{2} z_{1}^{3}+\theta_{3} b z_{1}^{2}+\theta_{4} a\right)$

Where $\theta_{i}$ and $\xi$ are nonlinear regression weights, with $\xi$ being a proportionality constant that does not impact on the elements of the cusp that appear within parentheses. $\operatorname{Pdf}(z)$ is the cumulative probability of the order parameter, $z$ (as $y$ ) is the order parameter that has been corrected for location and scale, $b$ is the bifurcation factor, and $a$ is the asymmetry factor. Like $z$, both $b$ and $a$ have been corrected for location and scale prior to inclusion in the equation. The arguments with the exponents describe the potential function for the cusp, with regression weights and a cubic term. When fitting the cusp model, optimal fit is achieved when all four nonlinear regression parameters are statistically significant. In the current study, we tested two different cusp catastrophe models, described by the two equations displayed bellow. Equations 3 and 4 describe the cusp catastrophe model of sickness absenteeism $(P d f(z))$ with workload as the bifurcation factor $\left(\theta_{3} W L z_{1}^{2}\right)$, and team adaptability $\left(\theta_{4} T A z_{1}\right)$ and task cohesion $\left(\theta_{4} T C_{2} z_{1}\right)$ as the asymmetry factors.

$$
\begin{aligned}
& P d f(z)=\xi \exp \left(\theta_{1} z_{1}^{4}+\theta_{2} z_{1}^{3}+\theta_{3} W L z_{1}^{2}+\theta_{4} T A z_{1}\right) \\
& P d f(z)=\xi \exp \left(\theta_{1} z_{1}^{4}+\theta_{2} z_{1}^{3}+\theta_{3} W L z_{1}^{2}+\theta_{4} T C_{2} z_{1}\right)
\end{aligned}
$$


When significance is not obtained for the quartic $\left(\theta_{1} z_{1}^{4}\right)$ and bifurcation $\left(\theta_{3} W L z_{1}^{2}\right)$ parameters, which are the fundamental parameters in the cusp catastrophe equation, the cubic $\left(\theta_{2} z_{1}^{3}\right)$ and the proportionality constant $(\xi)$ terms can be dropped to further examine if that improves model fit and allows to reach significance for the quartic and bifurcation parameters (for additional details, please regard Guastello, 2014, 2011). Additionally, if the $R^{2}$ decreases and statistical significance is still not reached for the quartic $\left(\theta_{1} z_{1}^{4}\right)$ and bifurcation $\left(\theta_{3} W L z_{1}^{2}\right)$ parameters, an alternative catastrophe model can be run where the former bifurcation factor becomes the new asymmetry factor $\left(\theta_{4} W L_{2} z_{1}\right)$, and the former asymmetry factor becomes the new bifurcation factor $\left(\theta_{3} T A z_{1}^{2}\right)$.

$P d f(z)=\xi \exp \left(\theta_{1} z_{1}^{4}+\theta_{2} z_{1}^{3}+\theta_{3} T A z_{1}^{2}+\theta_{4} W L_{2} z_{1}\right)$

When all parameters obtain statistical significance, or at least the quartic $\left(\theta_{1} z_{1}^{4}\right)$ and bifurcation $\left(\theta_{3} T A z_{1}^{2}\right)$ parameters do, it can be assumed that all the local dynamics of the model are true (Guastello, 2011). The static nonlinear regressions method is easily implemented with the help of a syntax file in SPSS Statistics (see Guastello, 2011).

Besides estimating the cusp model for sickness absenteeism using the direct method (Guastello, 2002), additional calculations were performed using the indirect method which also implements the cusp $p d f$ and uses the maximum likelihood estimation of the parameters (Cobb \& Watson, 1980). The indirect method using maximum likelihood estimation allows researchers more flexibility in the definition of the role that each parameter will play in the cusp catastrophe model. It also allows researchers to test for cusp catastrophe models with multiple bifurcation and asymmetry factors (Grasman, van der Maas, \& Wagenmakers, 2009). The major disadvantage over the direct estimation method is that the indirect estimation method is more demanding since it includes more parameters during the estimation process (Guastello, 2011). 
In the indirect method, the statistical significance of the cusp model is determined by the values of the pseudo- $R^{2}$ of the cusp model and the logistic model, compared against the $R^{2}$ of the linear regression model. Since the pseudo- $R^{2}$ is not a trustworthy guide in selecting the best model, it should be regarded with additional model fit indices that guide the assessment of model fit (Grasman et al., 2009). These are the Akaike's criterion (AIC), Akaike's criterion corrected for small samples $\left(\mathrm{AIC}_{\mathrm{c}}\right)$, and Bayes information criteria $(\mathrm{BIC})$ indices. The estimation of the cusp model following the maximum likelihood estimation procedure can be performed in the R package "cusp" (Grasman, van der Maas, \& Wagenmakers, 2009). In the indirect method estimation, sickness absenteeism was included as the control parameter $y$, while workload, team adaptability, and task cohesion were simultaneously included as bifurcation $b$, and asymmetry factors $a_{1}$ and $a_{2}$. In this study, we have regarded both methods since they complement each other (e.g. Dimas et al., 2019; Rebelo et al., 2016). Additionally, although the indirect method is more flexible, it might be regarded as a resilience test to the direct method too.

\section{Results}

Table 1 presents the correlations, descriptive statistics and aggregation indexes for the variables in this study. Before proceeding with data aggregation, we examined the within-group agreement index $r_{\mathrm{wg}(\mathrm{j})}$ (James, Demaree, \& Wolf, 1984) and the intra-class correlation coefficients (ICCs), ICC (1) and ICC (2) (Bliese, 2000), to decide whether to proceed with data aggregation. The within-group agreement index results for task cohesion, $r_{\mathrm{wg}(\mathrm{j})}=.77$, and team adaptability, $r_{\mathrm{wg}(\mathrm{j})}=.95$, were acceptable (James et al., 1984). The intra-class correlation indexes for task cohesion, $\operatorname{ICC}(1)=.05, \operatorname{ICC}(2)=.29$, and team adaptability, $\operatorname{ICC}(1)=.13$, ICC $(2)=.56$, were also acceptable. The fact that ICC (2) scores were below the recommended threshold of .70 can be explained by our small sample size. Bliese (2000) argues that small ICC (2) values are not any impediment to data aggregation. What may happen is that for constructs 
with low ICC (2), the strength of the relationship between research variables might be attenuated. Thus, low ICC (2) values may have made the testing of team-level relationships somewhat conservative. Additionally, ICC (2) values need to be higher than the values of ICC (1) for acceptance (Bliese, 2000), as it was the case.

The results presented in Table 1 also suggest that workload was uncorrelated with task cohesion, team adaptability and sickness absenteeism. The results also suggest that while task cohesion was positively correlated with team adaptability, $r=.74, p<.001$, both variables were negatively correlated with some measures of sickness absenteeism (t1 trough 3$), r \leq-.47, p<$ .05 .

<Insert Table 1 here>

\section{Hypotheses testing}

The results displayed in Table 2 and Table 3 summarize the research findings for the testing of the cusp catastrophe model of sickness absenteeism using nonlinear regression (Guastello, 2002). The overall $R^{2}$ of the cusp model for sickness absenteeism with all four nonlinear regression parameters, with workload as the bifurcation factor and team adaptability as the asymmetry factor was $.74, F(5,236)=227.714, p<.001$ (Cusp model). The cusp model reached a larger $R^{2}$ than the two linear models $\left(R^{2}\right.$ Linear $=.05 ; R^{2}$ Linear interaction $\left.=.05\right)$. However, since the bifurcation factor did not reach statistical significance, $\theta_{3} b z^{2}, p>.05$, we followed recommendations by Guastello $(2014,2016)$ and dropped the cubic term $\theta_{2} z^{3}$ since it is not a fundamental feature of the cusp catastrophe. The simplification of the cusp model rendered a $R^{2}=.59$, with only the coefficients of the bifurcation and asymmetry parameters achieving statistical significance in the positive direction (Cusp model a). However, after this modification the quartic term lost significance, which means that there was no support for a cusp catastrophe distribution in sickness absenteeism. 
Similar to other analytical procedures such as random coefficient modelling (Bliese \& Ployhart, 2002), Guastello (2011) suggests that when fitting the cusp model, one should always look for the optimal parameter arrangement that allows a full description of the complex system under examination. This means that even when the initially hypothesised dynamics are not observed, alternative cusp catastrophe models could be tested to determine if different arrangements in the control parameters lead to distinct dynamics in the order parameter. In that sense, we tested an alternative cusp catastrophe model with team adaptability as the bifurcation factor and workload as the asymmetry factor. Contradicting our original hypothesis, it could be that the extent to which team adaptability relates with sickness absenteeism only happens for very specific values of adaptability, whereas workload change is proportional to sickness absenteeism change. This would suggest a change in roles, with team adaptability functioning as the bifurcation factor and workload as the asymmetry factor.

When testing for this alternative arrangement, the overall $R^{2}$ of the cusp model for sickness absenteeism with all four nonlinear regression parameters, with team adaptability as the bifurcation factor and workload as the asymmetry factor was $.71, F(5,236)=194.375, p<$ .001 (Cusp model b), with all four parameters reaching statistical significance. The results displayed in Table 2 show that the quartic factor $\left(\theta_{1 z 1^{4}}\right)^{4}$ was statistically significant, and that both bifurcation $\left(\theta_{3} b z^{2}\right)$ and asymmetry $\left(\theta_{4} a z\right)$ factors were significant, such that higher levels of team adaptability and workload contributed to the discontinuity of the cusp response surface. These results suggest that when team adaptability is regarded as a bifurcation factor and workload is regarded as an asymmetry factor, change in sickness absenteeism follows a cusp catastrophe distribution. The negative value of the quartic term $\left(\theta_{1} z^{4}\right)$ suggests that shifts to not being sick absent from work were more frequent than shifts to being sick absent from work. Figures 4 and 5 further illustrates these findings. 
The $R^{2}$ of the cusp model with task cohesion as the asymmetry factor, $R^{2}=.75, F(5$, 236) $=228.857, p<.001$, was higher than the linear and linear interaction models $\left(R^{2}>.07\right)$. As expected, all four parameters were statistically significant. The results displayed in Table 3 suggest that workload functioned as a bifurcation factor $\left(\theta_{3} b z^{2}\right)$ and task cohesion functioned as an asymmetry factor $\left(\theta_{4} a z\right)$, such that high levels of workload and task cohesion contributed to the discontinuity of the cusp response surface. As before, the negative value of the quartic term $\left(\theta_{1} z^{4}\right)$ suggests that shifts to not being sick absent from work were more frequent than shifts to being sick absent from work. Figures 4 and 5 further illustrates these findings.

\section{<Insert Table 4 here>}

To further examine the nonlinear dynamics of sickness absenteeism in firefighter teams, we have also run the cusp catastrophe model of sickness absenteeism using maximum likelihood (Cobb \& Watson, 1980). The results in Table 4 suggest that the cusp model with workload as the bifurcation factor, task cohesion as the asymmetry factor, and team adaptability as a bifurcation factor explains more variance in the data $\left(R^{2}=.38\right)$ than the linear $\left(R^{2}=.07\right)$ and logistic models $\left(R^{2}=.17\right)$. The differences between the cusp and the linear model are further substantiated by the $\chi^{2}$ difference test that supports that the linear and the cusp model are significantly different from each other; and the model fit statistics provided by the AIC, AICc, and BIC indexes. Still, the logistic model has a small better fit than the cusp and linear models. The results displayed in Table 4 also suggest that low levels of workload, team adaptability, and task cohesion contribute to the discontinuity of the cusp response surface. Figures 4 and 5 show the two-dimensional and three-dimensional cusp catastrophe $p d f$ for sickness absenteeism in firefighter teams.

The research findings offer general support to our initial argument that change in sickness absenteeism is nonlinear, and that team resources are asymmetry factors. Hence, hypotheses 1 and 2 were supported. However, the results are also mixed in what regards the 
role of workload and team adaptability as bifurcation and asymmetry factors. In the following section, we elaborate on the potential implications of these results.

<Insert Figure 4 here>

<Insert Figure 5 here>

\section{Discussion}

Our study analysed whether workload as a job demand and contextual dynamic, and team adaptability and task cohesion as team resources and global dynamics related with the nonlinear dynamics of change in sickness absenteeism of firefighters. We found that sickness absenteeism changes nonlinearly, and that cusp catastrophe models explain such nonlinearly beyond linear and logistic models. This finding may help explaining why previous studies on sickness absenteeism have found support to distinct dynamics (e.g. Hausknecht et al., 2008). Our results also suggest that workload and team adaptability explain incremental and discontinuous change in sickness absenteeism, whereas task cohesion seems to mainly explain incremental change. These findings have implications for both theory and practice that we discuss below.

\section{Theoretical Implications}

First, the outcomes of this work contribute to the teamwork literature in nonlinear dynamics, the extension to the JD-R model to the team level, and the integration of the tCAS and the JDR model in the context of action teams, within the NDS framework. In this regard, despite the potential gain in learning how sickness absenteeism behaviours change over time (e.g. which trajectories it might take), the number of studies addressing this particular issue remains scarce. Differently, in our study we found general support for the argument that the dynamics of sickness absenteeism are truly chaotic, and that such dynamics fit a cusp catastrophe model when considering task cohesion as an asymmetry factor, workload as a bifurcation factor, and team adaptability as a dual factor functioning both as an asymmetry and a bifurcation factor. 
In addition, in light of the teamwork implications of the JD-R model, our findings suggest that the dynamics of sickness absenteeism are driven by the contextual and local dynamics of teams, namely team resources and job demands. Thus, a key takeaway message could be that teamwork local dynamics do indeed display dynamic properties, further supporting tCAS approach and highlighting the importance of studying team dynamics beyond the linear paradigm (Ramos-Villagrasa, Navarro, \& García-Izquierdo, 2012). Although unexpected, we found other interesting relationships that expand the JD-R model, integrating it with the tCAS; that is, the dual role of workload and team adaptability in explaining continuous and discontinuous change in sickness absenteeism over time. Although we did not account for the characteristics of the events that firefighter teams had to solve, nor did we measured team members perceptions of task complexity or task load, it could be that the characteristics of the event itself might help explaining the duality that we have found regarding workload and team adaptability.

Our results also show that team adaptability and task cohesion work as resources for teams performing in high-demand environments. Our findings suggest that in teams with strong social ties, stable structures and support perceptions, team members were less prone to engage in sickness absenteeism behaviours. This finding offers great support to the general claim that cohesion keeps team members together and prevents team dismantling (Beal et al., 2003). These findings also parallel Hackman's (2012) enabling conditions idea that effective teamwork requires the existence of an optimal set of conditions enabling teams to achieve their highest performance. When these conditions are not met, teams are less effective.

Finally, our findings present additional implications if we consider them from the healthy variability principle (Ashby, 1956) resulting from combining both tCAS and the team level JD-R model. The healthy variability principle states that "healthy functioning systems have chaotic fluctuations, whereas unhealthy functioning systems present fewer fluctuations 
and, very often, show linear and predictable patterns of behaviour" (Navarro \& Rueff-Lopes, 2015 , p. 530). The principle of healthy variability aligns with the minimum entropy principle, which suggests that living and social systems need a minimum degree of variability in order to perform as a complex and adaptive system (Arrow et al., 2000; Guastello et al., 2013). Combining these principles, we can see how different paired values the team resources and job demands led to continuous and discontinuous change in sickness absenteeism over time.

\section{Practical Implications}

For action teams such as firefighters, our findings advise that measuring certain team characteristics (e.g. adaptability or task cohesion) at specific points in the team performance cycle (e.g. half-way point) helps in predicting sickness absenteeism evolution. Our findings further suggest that nonlinear modelling techniques should be considered to improve measurement accuracy regarding change in sickness absenteeism. Monitoring how sickness absenteeism behaviours change over time may allow in developing predictive models (and tools) that would warn when sickness absenteeism behaviours are likelier to happen. Such warnings would allow the HR Management Department, the psychological support team, or the team leader to deploy countermeasures to be more vigilant about these issues and either prevent or attenuate sickness absenteeism. Furthermore, our findings suggest that an effective strategy to prevent sickness absenteeism behaviours in firefighting teams could connect team adaptability and task cohesion. A way to increase team adaptability is through perturbation training (Gorman et al., 2010). Such training is designed in a way that forces team members to learn new ways to overcome a given obstacle. If accompanied with a team learning approach that combines feedback and reflexivity, team adaptability is likely to build up (Gabelica, Van den Bossche, De Maeyer, Segers, \& Gijselaers, 2014).

Finally, our findings may also have implications for teams performing in isolated, confined and extreme environments (e.g. Maynard et al., 2018). As an example, if planning an 
over-winter mission to Antarctica, measuring team resources such as team adaptability and task cohesion before the start of the mission may help to predict the evolution of teamwork-related outcomes throughout the mission. Indeed, cusp catastrophe models allow very precise forecasts of when radical shifts in the state of the system will happen (Guastello, 2014). This means that such models could be used to predict which values of workload, team adaptability and task cohesion make team members more likely to (dis)engage in(from) sickness absenteeism. This will allow HR managers and mission managers to design and implement effective policies to mitigate negative work-related outcomes such as negative affect.

\section{Research limitations and future directions}

This study is not free from limitations. One limitation would be the specificity of the research context in which our research was conducted, which could limit the generalizability of our findings. However, regardless of the specificities of firefighter teams, they are real action teams and therefore the lessons learned from this study can directly apply to other action teams such as military, Special Forces or search and rescue groups (Devine, 2002). Furthermore, although the sources of strain might be different, the lessons learned from this research can also be transferred to blue- and white-collar professional occupations where team members often perform under stress, make urgent and critical decisions and act in an interdependent and coordinated way (Devine, 2002).

Another limitation in this study would be the fact that we were unable to control for all the psychological and contextual variables that could help to explain the temporal dynamics of sickness absenteeism over time. For instance, we did not know teams' previous trajectories of sickness absenteeism or workload, which could be relevant to predict its further evolution from the moment of data collection onward (Ferguson, 1972; Navarro et al., 2015). Furthermore, Bedwell et al. (2014) suggest that the subjective and objective experience of workload is greatly determined by the team workload capacity (i.e. "the potential amount of taskwork and 
teamwork that teams can engage in, if all members of the team are optimally applying their resources (or characteristics) to the work at hand when output quality is crucial", p. 103). This capacity results from the combination of team (e.g. team potency) and task characteristics, and work context characteristics. Hence, future research may look at the role of workload capacity over the temporal relationship between workload and sickness absenteeism. In this regard, cusp catastrophe modelling could be of help in identifying the tipping point in which task workload and/or team workload exceed team workload capacity, contingent on the characteristics of the events that firefighters are asked to solve (Ramos-Villagrasa et al., 2018).

Finally, another interesting extension of the current study would be the consideration of team characteristics such as team identity, team tenure, and the extent to which team members perceive events as being challenging versus hindering. For example, team identity can determine the extent to which cohesion emerges (Murrel \& Gaertner, 1992). In this regard, an interesting experiment would be looking into the role of team identity regarding the emergence of team, task cohesion and social cohesion, and to examine to what extent the temporal dynamics of sickness absenteeism are related to these. Since team identity can be regarded as proxy of team cohesion, it could be that teams that have higher group identity will develop higher cohesion faster than teams with weaker identity (Burke et al., 2006). Also, while our sample's team tenure was relatively high, it would be interesting to see if our findings hold under conditions where team members have less experience working together. Under low team tenure conditions, job resources such as team adaptability and task cohesion may be less developed since teams spent less time together (Burke et al., 2006). Finally, the events to which the teams were responding could be perceived by firefighters as a challenging (as opposed to a hindering) job demands (Tadic, Bakker, \& Oerlemans, 2015). Perceived challenging demands, despite consuming energy, also stimulate workers' curiosity, competence and thoroughness (van der Broek et al, 2009), eliciting a problem-focused coping style and promoting need 
satisfaction. Indeed, some studies on work overload found it to be positively related to engagement over time (e.g. Bakker et al., 2003; Van den Broeck, Vansteenkiste, De Witte, \& Lens, 2008).

\section{Conclusion}

Fully understanding how teams operate in the wild requires their consideration as complex adaptive systems displaying nonlinear behaviour. For firefighter teams, the level of contextual dynamics (as job demands) and global dynamics (as team resources) determines smooth, as well as sudden change in sickness absenteeism over time. 


\section{References}

Ângelo, R. P., \& Chambel, M. J. (2015). The reciprocal relationship between work characteristics and employee burnout and engagement: A longitudinal study of firefighters. Stress and Health, 31(2), 106-114. doi: 10.1002/smi.2532

Arrow, H., McGrath, J. E., \& Berdahl, J. L. (2000). Small groups as complex systems: Formation, coordination, development, and adaptation. London, UK: Sage Publications.

Ashby, R. W. (1956). An introduction to cybernetics. London, UK: Methuen.

Bakker, A. B., \& Demerouti, E. (2017). Job demands-resources theory: Taking stock and looking forward. Journal of Occupational Health Psychology, 22(3), 273-285. doi: 2016-48454-001

Bakker, A. B., Demerouti, E., De Boer, E., \& Schaufeli, W. B. (2003). Job demands and job resources as predictors of absence duration and frequency. Journal of Vocational Behavior, 62(2), 341-356. doi: 10.1016/S0001-8791(02)00030-1

Balkundi, P., \& Harrison, D. A. (2006). Ties, leaders, and time in teams: Strong inference about network structure's effects on team viability and performance. Academy of Management Journal, 49(1), 49-68. doi: 10.5465/amj.2006.20785500

Beal, D. J., Cohen, R. R., Burke, M. J., \& McLendon, C. L. (2003). Cohesion and performance in groups: A meta-analytic clarification of construct relations. Journal of Applied Psychology, 88(6), 989-1004. doi: 2003-09785-002 
Bedwell, W. L., Salas, E., Funke, G. J., \& Knott, B. A. (2014). Team workload: A multilevel perspective. Organizational Psychology Review, 4(2), 99-123. doi:

$10.1177 / 2041386613502665$

Bliese, P. D. (2000). Within-group agreement, non-independence, and reliability: Implications for data aggregation and analysis. In J. Klein \& S. W. J. Kozlowski (Eds.), Multilevel theory, research, and methods in organizations: Foundations, extensions, and new directions (pp. 349-381). San Francisco, CA, US: Jossey-Bass.

Bliese, P. D., \& Ployhart, R. E. (2002). Growth modeling using random coefficient models: Model building, testing, and illustrations. Organizational Research Methods, 5(4), 362-387. doi: $10.1177 / 109442802237116$

Boos, M., Pritz, J., Lange, S., \& Belz, M. (2014). Leadership in moving human groups. PLoS Computational Biology, 10(4), e1003541.

Burke, C. S., Stagl, K. C., Salas, E., Pierce, L., \& Kendall, D. (2006). Understanding team adaptation: A conceptual analysis and model. Journal of Applied Psychology, 91(6), 1189-1207. doi: 10.1037/0021-9010.91.6.1189

Carless, S. A., \& De Paola, C. (2000). The measurement of cohesion in work teams. Small Group Research, 31(1), 71-88. doi: 10.1177/104649640003100104

Ceja, L., \& Navarro, J. (2012). 'Suddenly I get into the zone': Examining discontinuities and nonlinear changes in flow experiences at work. Human Relations, 65(9), 1101-1127. doi: $10.1177 / 0018726712447116$

Christian, J. S., Christian, M. S., Pearsall, M. J., \& Long, E. C. (2017). Team adaptation in context: An integrated conceptual model and meta-analytic review. Organizational Behavior and Human Decision Processes, 140, 62-89. doi: S0749597815302879

Cobb, L., \& Watson, B. (1980). Statistical catastrophe theory: An overview. Mathematical Modelling, 1(4), 311-317. doi: 10.1016/0270-0255(80)90041-X 
Cohen-Hatton, S. R., Butler, P. C., \& Honey, R. C. (2015). An investigation of operational decision making in situ: Incident command in the UK fire and rescue service. Human Factors, 57(5), 793-804. doi: 10.1177/0018720815578266

Contractor, N. S., DeChurch, L. A., Carson, J., Carter, D. R., \& Keegan, B. (2012). The topology of collective leadership. The Leadership Quarterly, 23(6), 994-1011. doi: 10.1016/j.leaqua.2012.10.010

Costa, P. L., Passos, A. M., \& Bakker, A. B. (2014). Team work engagement: A model of emergence. Journal of Occupational and Organizational Psychology, 87(2), 414-436. doi: 10.1111/joop.12057

Costa, P. L., Passos, A. M., \& Bakker, A. B. (2015). Direct and contextual influence of team conflict on team resources, team work engagement, and team performance. Negotiation and Conflict Management Research, 8(4), 211-227. doi: $10.1111 / \mathrm{ncmr} .12061$

Cronin, M. A., Weingart, L. R., \& Todorova, G. (2011). Dynamics in groups: Are we there yet? The academy of Management Annals, 5(1), 571-612. Doi: $10.1080 / 19416520.2011 .590297$

Curral, L., Marques-Quinteiro, P., Gomes, C., \& Lind, P. G. (2016). Leadership as an emergent feature in social organizations: insights from a laboratory simulation experiment. PloS one, 11(12), e0166697.

Darr, W., \& Johns, G. (2008). Work strain, health, and absenteeism: a meta-analysis. Journal of Occupational Health Psychology, 13(4), 293-318. doi: 10.1037/a0012639

DeGroot, M. H. (1986). Probability and Statistics (2ºd). Addison-Wesley. pp. 258-259. ISBN 0-201-11366-X.

Dekkers-Sánchez, P. M., Hoving, J. L., Sluiter, J. K., \& Frings-Dresen, M. H. (2007). Factors associated with long-term sick leave in sick listed employees: A systematic review. 
Occupational and Environmental Medicine, 65(3), 153-157. doi:

10.1136/oem.2007.034983

Demerouti, E., Bakker, A. B., Nachreiner, F., \& Schaufeli, W. B. (2001). The job demandsresources model of burnout. Journal of Applied Psychology, 86(3), 499-512.

Devine, D. J. (2002). A review and integration of classification systems relevant to teams in organizations. Group Dynamics: Theory, Research, and Practice, 6(4), 291-310. doi: 10.1037/1089-2699.6.4.291

de Reuver, R., Van de Voorde, K., \& Kilroy, S. (2019). When do bundles of high performance work systems reduce employee absenteeism? The moderating role of workload. The International Journal of Human Resource Management, 1-21. Advanced online publication. doi: 10.1080/09585192.2019.1616594

Dimas, I. D., Rebelo, T., Lourenço, P. R., \& Rocha, H. (2019, July). A Nonlinear Dynamical System Perspective on Team Learning: The Role of Team Culture and Social Cohesion. In International Conference on Computational Science and Its Applications (pp. 38-49). Springer, Cham.

Ellis, A. P., \& Pearsall, M. J. (2011). Reducing the negative effects of stress in teams through cross-training: A job demands-resources model. Group Dynamics: Theory, Research, and Practice, 15(1), 16-31. doi: 2011-02126-001

Ferguson, D. (1972). Some characteristics of repeated sickness absence. Occupational and Environmental Medicine, 29(4), 420-431.

Gabelica, C., Van den Bossche, P., De Maeyer, S., Segers, M., \& Gijselaers, W. (2014). The effect of team feedback and guided reflexivity on team performance change. Learning and Instruction, 34, 86-96. doi: 10.1016/j.learninstruc.2014.09.001 
Gersick, C. J. (1991). Revolutionary change theories: A multilevel exploration of the punctuated equilibrium paradigm. Academy of Management Review, 16(1), 10-36. doi: 10.5465/AMR.1991.4278988

Gorman, J. C., Cooke, N. J., \& Amazeen, P. G. (2010). Training adaptive teams. Human Factors, 52(2), 295-307. doi: 10.1177/0018720810371689

Grasman, R., van der Maas, H. L., \& Wagenmakers, E. J. (2009). Fitting the cusp catastrophe in R: A cusp package primer. Journal of Statistical Software, 32(i08). doi: 10.18637/jss.v032.108

Guastello, S. J., Correro II, A. N., \& Marra, D. E. (2019). Cusp catastrophe models for cognitive workload and fatigue in teams. Applied Ergonomics, 79, 152-168. doi: 10.1016/j.apergo.2018.08.019

Guastello, S. J., Gorin, H., Huschen, S., Peters, N. E., Fabisch, M., Poston, K., \& Weinberger, K. (2013). The minimum entropy principle and task performance. Nonlinear Dynamics, Psychology, and Life Sciences, 17(3), 405-423.

Guastello, S. J., Boeh, H., Schimmels, M., Gorin, H., Huschen, S., Davis, E., ... \& Poston, K. (2012). Cusp catastrophe models for cognitive workload and fatigue in a verbally cued pictorial memory task. Human factors, 54(5), 811-825. doi: $10.1177 / 0018720812442537$

Guastello; S. J. (2011). Catastrophe models with nonlinear regression. In S. J., Guastello, \& R. A., Gregson, R. A. (Eds.), Nonlinear dynamical systems analysis for the behavioral sciences using real data. FL: USA. CRC Press.

Guastello, S. J., \& Liebovitch, L. S. (2009). Introduction to nonlinear dynamics and complexity. In S. J. Guastello, M. Koopmans, \& D. Pincus (Eds.), Chaos and complexity in psychology: The theory of nonlinear dynamical systems (pp. 1-40). New York, NY, US: Cambridge University Press. 
Guastello, S. J. (2001). Nonlinear dynamics in psychology. Discrete Dynamics in Nature and Society, 6(1), 11-29. doi: 10.1155/S1026022601000024

Guastello, S. J., \& Guastello, D. D. (1998). Origins of coordination and team effectiveness: A perspective from game theory and nonlinear dynamics. Journal of Applied Psychology, 83(3), 423-437. doi: 1998-02893-006

Hackman, J. R. (2012). From causes to conditions in group research. Journal of Organizational Behavior, 33(3), 428-444. doi: 10.1002/job.1774

Hart, S. G., \& Staveland, L. E. (1988). Development of NASA-TLX (Task Load Index): Results of empirical and theoretical research. In Advances in Psychology, 52, 139183. doi: 10.1016/S0166-4115(08)62386-9

Hausknecht, J. P., Hiller, N. J., \& Vance, R. J. (2008). Work-unit absenteeism: Effects of satisfaction, commitment, labor market conditions, and time. Academy of Management Journal, 51(6), 1223-1245. doi: 10.5465/AMJ.2008.35733022

Hensing, G., Alexanderson, K., Allebeck, P., \& Bjurulf, P. (1998). How to measure sickness absence? Literature review and suggestion of five basic measures. Scandinavian Journal of Social Medicine, 26(2), 133-144. doi: 10.1177/14034948980260020201

James, L. R., Demaree, R. G., \& Wolf, G. (1984). Estimating within-group interrater reliability with and without response bias. Journal of Applied Psychology, 69(1), 8598. doi: 10.1037/0021-9010.69.1.85

Kennedy, D. M., \& Maynard, M. T. (2017). It is about time: temporal considerations of team adaptation. In E. Salas, W. B. Vessey, \& L. B. Landon (Eds.), Team dynamics over time (pp. 29-49). USA: Emerald Publishing Limited.

Kozlowski, S. W., Chao, G. T., Grand, J. A., Braun, M. T., \& Kuljanin, G. (2016). Capturing the multilevel dynamics of emergence: Computational modeling, simulation, and 
virtual experimentation. Organizational Psychology Review, 6(1), 3-33. Doi: $10.1177 / 2041386614547955$

Kozlowski, S. W., \& Chao, G. T. (2012). The dynamics of emergence: Cognition and cohesion in work teams. Managerial and Decision Economics, 33(5-6), 335-354. doi: $10.1002 /$ mde. 2552

Kozlowski, S. W. J., Gully, S. M., Salas, E., \& Cannon-Bowers, J. A. (1996). Team leadership and development: Theory, principles, and guidelines for training leaders and teams. In M. M. Beyerlein, D. A. Johnson, \& S. T. Beyerlein (Eds.), Advances in interdisciplinary studies of work teams: Team leadership, (Vol. 3, pp. 253-291). US: Elsevier Science/JAI Press.

Kuoppala, J., Lamminpää, A., \& Husman, P. (2008). Work health promotion, job well-being, and sickness absences - a systematic review and meta-analysis. Journal of Occupational and Environmental Medicine, 50(11), 1216-1227. doi: 10.1097/JOM.0b013e31818dbf92

LePine, J. A. (2005). Adaptation of teams in response to unforeseen change: effects of goal difficulty and team composition in terms of cognitive ability and goal orientation. Journal of Applied Psychology, 90(6), 1153. doi: 10.1037/00219010.90.6.1153

Marks, M. A., Mathieu, J. E., \& Zaccaro, S. J. (2001). A temporally based framework and taxonomy of team processes. Academy of Management Review, 26(3), 356-376. doi: 10.5465/AMR.2001.4845785

Marques-Quinteiro, P., Curral, L., Passos, A. M., \& Lewis, K. (2013). And now what do we do? The role of transactive memory systems and task coordination in action teams. Group Dynamics: Theory, Research, and Practice, 17(3), 194-206. doi: 2013-30650003 
Marques-Quinteiro, P., Ramos-Villagrasa, P. J., Passos, A. M., \& Curral, L. (2015). Measuring adaptive performance in individuals and teams. Team Performance Management, 21(7/8), 339-360. doi: 10.1108/TPM-03-2015-0014

Mathieu, J. E., Gallagher, P. T., Domingo, M. A., \& Klock, E. A. (2019). Embracing complexity: reviewing the past decade of team effectiveness research. Annual Review of Organizational Psychology and Organizational Behavior, 6, 17-46. doi: 10.1146/annurev-orgpsych-012218-015106

Maynard, M. T., Kennedy, D. M., \& Ressick, C. J. (2018). Teamwork in extreme environments: Lessons, challendges, and opportunities. Journal of Organizational Behavior, 39(6), 695-700. doi: 10.1002/job.2302

Maynard, M. T., Kennedy, D. M., \& Sommer, S. A. (2015a). Team adaptation: A fifteen-year synthesis (1998-2013) and framework for how this literature needs to "adapt" going forward. European Journal of Work and Organizational Psychology, 24(5), 652-677. doi: 10.1080/1359432X.2014.1001376

Maynard, M. T., Kennedy, D. M., Sommer, S. A., \& Passos, A. M. (2015b). Team cohesion: A theoretical consideration of its reciprocal relationships within the team adaptation nomological network. In E. Salas, W. B. Vessey, \& A. X. Estrada (Eds.), Team cohesion: Advances in psychological theory, methods and practice (pp. 83-111). USA: Emerald Group Publishing Limited.

Navarro, J., Roe, R. A., \& Artiles, M. I. (2015). Taking time seriously: Changing practices and perspectives in work/organizational psychology. Journal of Work and Organizational Psychology, 31, 135-145. doi: 10.1016/j.rpto.2015.07.002 1576-5962

Navarro, J., \& Rueff-Lopes, R. (2015). Healthy variability in organizational behavior: Empirical evidence and new steps for future research. Nonlinear Dynamics, Psychology, and Life Sciences, 19(4), 529-552. 
Ramos-Villagrasa, P. J., Marques-Quinteiro, P., Navarro, J., \& Rico, R. (2018). Teams as complex adaptive systems: Reviewing 17 years of research. Small Group Research, 49(2), 135-176. doi: 10.1177/1046496417713849

Ramos-Villagrasa, P. J., Navarro, J., \& García-Izquierdo, A. L. (2012). Chaotic dynamics and team effectiveness: Evidence from professional basketball. European Journal of Work and Organizational Psychology, 21(5), 778-802. doi:

$10.1080 / 1359432 X .2012 .669525$

Rebelo, T., Stamovlasis, D., Lourenço, P. R., Dimas, I., \& Pinheiro, M. (2016). A cusp catastrophe model for team learning, team potency and team culture. Nonlinear Dynamics, Psychology, and Life Sciences, 20(4), 537-563.

Roe, R. A. (2008). Time in applied psychology: The study of "what happens" rather than "what is". European Psychologist, 13(1), 37-52. doi: 10.1027/1016-9040.13.1.37

Schaufeli, W. B., Bakker, A. B., \& Van Rhenen, W. (2009). How changes in job demands and resources predict burnout, work engagement, and sickness absenteeism. Journal of Organizational Behavior, 30(7), 893-917. doi: 10.1002/job.595

Sheridan, J. E. (1985). A catastrophe model of employee withdrawal leading to low job performance, high absenteeism, and job turnover during the first year of employment. Academy of Management Journal, 28(1), 88-109. soi: 10.5465/256063

Sundstrom, E. D. (1999). Supporting work team effectiveness: Best management practices for fostering high performance (pp. 3-23). San Francisco: USA. Jossey-Bass Publishers.

Szubert, Z., \& Sobala, W. (2002). Work-related injuries among firefighters: Sites and circumstances of their occurrence. International Journal of Occupational Medicine and Environmental Health, 15(1), 49-55.

Tadic, M., Bakker, A. B., \& Oerlemans, W. G. M. (2015). Challenge versus hindrance job demands and well-being : a diary study on the moderating role of job resources. 
Journal of Occupational and Organizational Psychology, 88(4), 702-725. DOI: 10.1111/joop.12094

The Guardian (2018). Grenfell Tower should not have been lived in, fire chief tells inquiry. Retrieved from https://www.theguardian.com/uk-news/2018/sep/25/grenfell-towershould-not-have-been-lived-in-fire-chief-tells-inquiry

Uitdewilligen, S., Rico, R., \& Waller, M. J. (2018). Fluid and stable: Dynamics of team action patterns and adaptive outcomes. Journal of Organizational Behavior, 39(9), 1113-1128. doi: 10.1002/job.2267

Urien, B., Rico, R., Demerouti, E., \& Bakker, A. (2017). Job demands and resources model at the team level. Paper presented at the $18^{\text {th }}$ EAWOP Conference, Dublin, Ireland.

Van den Broeck, A., Vansteenkiste, M., De Witte, H., \& Lens, W. (2008). Explaining the relationships between job characteristics, burnout, and engagement: The role of basic psychological need satisfaction. Work \& Stress, 22(3), 277-294. doi:

$10.1080 / 02678370802393672$

Xanthopoulou, D., Bakker, A. B., Demerouti, E., \& Schaufeli, W. B. (2007). The role of personal resources in the job demands-resources model. International Journal of Stress Management, 14(2), 121-141. doi: 10.1037/1072-5245.14.2.121

Zaccaro, S. J., Gualtieri, J., \& Minionis, D. (1995). Task cohesion as a facilitator of team decision making under temporal urgency. Military Psychology, 7(2), 77-93. doi: 10.1207/s15327876mp0702_1

Zeeman, E. C. (1979). Catastrophe theory. In Structural Stability in Physics (pp. 12-22). Springer, Berlin, Heidelberg. 
Table 1

Variable correlations, descriptive statistics and aggregation indexes.

\begin{tabular}{|c|c|c|c|c|c|c|c|c|c|c|c|c|c|c|c|c|c|c|c|c|}
\hline & 1 & 2 & 3 & 4 & 5 & 6 & 7 & 8 & 9 & 10 & 11 & 12 & 13 & 14 & 15 & $M$ & $S D$ & \multicolumn{3}{|c|}{$r_{\mathrm{wg}(\mathrm{j})} \mathrm{ICC} 1 \mathrm{ICC} 2$} \\
\hline $\begin{array}{l}\text { 1. Team adaptability, } \\
\text { t0 }\end{array}$ & 1 & - & - & - & - & - & - & - & - & - & - & - & - & - & - & 4.00 & 0.37 & .95 & .13 & .56 \\
\hline 2. Task cohesion, t0 & $.74 * * *$ & 1 & - & - & - & - & - & - & - & - & - & - & - & - & - & 3.99 & 0.40 & .77 & .05 & .29 \\
\hline 3. Initial Workload, t0 & -.18 & -.19 & 1 & - & - & - & - & - & - & - & - & - & - & - & - & 0.51 & 0.49 & - & - & - \\
\hline 4. Workload, $\mathrm{t} 1$ & -.17 & -.23 & $.85 * * *$ & 1 & - & - & - & - & - & - & - & - & - & - & - & 0.44 & 0.42 & - & - & - \\
\hline 5. Workload, t2 & -.16 & -.21 & $.72 * * *$ & $.84 * * *$ & 1 & - & - & - & - & - & - & - & - & - & - & 0.42 & 0.32 & - & - & - \\
\hline 6. Workload, t3 & -.17 & -.21 & $.85^{* * *}$ & $.95 * * *$ & $.86 * * *$ & 1 & - & - & - & - & - & - & - & - & - & 0.45 & 0.35 & - & - & - \\
\hline 7. Workload, t4 & -.15 & -.20 & $.87 * * *$ & $.92 * * *$ & $.85 * * *$ & $.87 * * *$ & 1 & - & - & - & - & - & - & - & - & 0.48 & 0.42 & - & - & - \\
\hline 8. Workload, t5 & -.17 & -.21 & $.84 * * *$ & $.76 * * *$ & $.73 * * *$ & $.72 * * *$ & $.92 * * *$ & 1 & - & - & - & - & - & - & - & 0.44 & 0.36 & - & - & - \\
\hline 9. Workload, t6 & -.16 & -.24 & $.61 * * *$ & $.91 * * *$ & $.77 * * *$ & $.86^{* * *}$ & $.81 * * *$ & $.61 * * *$ & 1 & - & - & - & - & - & - & 0.44 & 0.40 & - & - & - \\
\hline $\begin{array}{l}\text { 10. Initial sickness } \\
\text { absenteeism, t0 }\end{array}$ & .00 & .09 & .04 & .03 & .31 & .05 & .11 & .11 & .01 & 1 & - & - & - & - & - & 0.59 & 0.69 & - & - & - \\
\hline $\begin{array}{l}\text { 11. Sickness } \\
\text { absenteeism, t1 }\end{array}$ & $-.43 * *$ &.- & .09 & .03 & .27 & .07 & .15 & .22 & .04 & $.49 * *$ & 1 & - & - & - & - & 0.76 & 0.86 & - & - & - \\
\hline $\begin{array}{l}\text { 12. Sickness } \\
\text { absenteeism, t2 }\end{array}$ & $-.42 *$ & 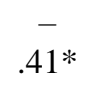 & -.03 & .00 & -.05 & .00 & -.01 & .07 & .04 & -.02 & $.48 * *$ & 1 & - & - & - & 0.70 & 0.97 & - & - & - \\
\hline $\begin{array}{l}\text { 13. Sickness } \\
\text { absenteeism, t3 }\end{array}$ & $-.47 * *$ &.- & .10 & .03 & -.06 & .12 & .04 & .13 & .04 & -.07 & $.37 *$ & $.71 * * *$ & $=1$ & - & - & 0.62 & 0.92 & - & - & - \\
\hline $\begin{array}{l}\text { 14. Sickness } \\
\text { absenteeism, t4 }\end{array}$ & .03 & -.18 & .07 & .12 & .10 & .21 & .06 & .06 & .13 & .04 & .04 & .13 & .30 & 1 & - & 0.30 & 0.52 & - & - & - \\
\hline $\begin{array}{l}\text { 15. Sickness } \\
\text { absenteeism, t5 }\end{array}$ & -.07 & -.27 & .28 & .17 & .24 & .26 & .21 & .18 & .09 & .15 & .29 & -.05 & .20 & $.44 * *$ & 1 & 0.61 & 0.81 & - & - & - \\
\hline $\begin{array}{l}\text { 16. Sickness } \\
\text { absenteeism, t6 }\end{array}$ & .20 & -.11 & -.12 & -.11 & -.17 & -.07 & -.16 & -.20 & $\begin{array}{l}- \\
.08 \\
\end{array}$ & -.11 & -.09 & -.07 & $\begin{array}{l}- \\
.09 \\
\end{array}$ & $.40^{*}$ & $.69 * * *$ & 0.67 & 0.77 & - & - & - \\
\hline
\end{tabular}

Note. $n=37$ teams. Two-tailed tests. $* * * p<.001 . * * p<.01 . * p<.05 . \mathrm{t}$ stands for time. 


\section{Table 2}

Results of the cusp model for sickness absenteeism with Nonlinear Regression estimation, with team adaptability as the asymmetry factor

\begin{tabular}{llll}
\hline Model & $R^{2}$ & $\beta$ & Model $F$
\end{tabular}

Sickness absenteeism

Linear model

.05

$6.594 * *$

Workload

.070

Team adaptability

$-.198 * *$

Linear interaction

.05

Workload

.081

Team adaptability

$-.175^{*}$

Interaction

.052

Cusp model

Sickness absenteeism $\left(\theta_{1} z^{4}\right)$

Cubic term $\left(\theta_{2} z^{3}\right)$

$120.287 * * *$

Workload $\left(\theta_{3} \mathrm{bz}^{2}\right)$

12.505

Team adaptability $\left(\theta_{4} a z\right)$

$11.413 * * *$

Cusp model a

.59

$158.272 * * *$

Sickness absenteeism $\left(\theta_{1} z^{4}\right)$

Workload $\left(\theta_{3} b z^{2}\right)$

$48.351^{*}$

Team adaptability $\left(\theta_{4} a z\right)$

$18.988 * * *$

Cusp model b

Sickness absenteeism $\left(\theta_{1} \mathrm{z}^{4}\right)$

$-224.694 * * *$

Cubic term $\left(\theta_{2} \mathrm{Z}^{3}\right)$

$116.698 * * *$

Team adaptability $\left(\theta_{3} b z^{2}\right)$

$27.249 * *$ 
Workload $\left(\theta_{4} a z\right)$

$10.500 *$

Note. ${ }^{*} p<0.05 ;{ }^{*} p<0.01 ; * * * p<0.001$ (two-tailed).

${ }^{a}$ After dropping the least essential element in the model, $\theta_{2} z^{3}$.

${ }^{\mathrm{b}}$ Alternative cusp model, with team adaptability as the bifurcation factor and workload as the asymmetry factor. 


\section{Table 3}

Results of the cusp model for sickness absenteeism with Nonlinear Regression estimation, with task cohesion as the asymmetry factor

\begin{tabular}{|c|c|c|c|}
\hline Model & $R^{2}$ & $\beta$ & Model $F$ \\
\hline \multicolumn{4}{|l|}{ Sickness absenteeism } \\
\hline Linear model & .07 & & $9.817 * * *$ \\
\hline Workload & & .052 & \\
\hline Task cohesion & & $-.251 * * *$ & \\
\hline Linear interaction & .07 & & $7.327 * * *$ \\
\hline Workload & & .083 & \\
\hline Task cohesion & & $-3.358 * *$ & \\
\hline Interaction & & .099 & \\
\hline Cusp model & .75 & & $228.857 * * *$ \\
\hline Sickness absenteeism $\left(\theta_{1} z^{4}\right)$ & & $-229.148 * * *$ & \\
\hline Cubic term $\left(\theta_{2} z^{3}\right)$ & & $123.433 * * *$ & \\
\hline Workload $\left(\theta_{3} b z^{2}\right)$ & & $20.598 * * *$ & \\
\hline Task cohesion $\left(\theta_{4} a z\right)$ & & $12.887 * * *$ & \\
\hline
\end{tabular}

Note. $\dagger p<.06 * p<0.05 ; * * p<0.01 ; * * * p<0.001$ (two-tailed). 
Table 4

Results of the cusp model for sickness absenteeism with Maximum Likelihood estimation $95 \% \mathrm{CI}$

\begin{tabular}{|c|c|c|c|c|c|}
\hline \multirow{2}{*}{ Model } & \multirow{2}{*}{ B } & \multirow{2}{*}{ S.E } & \multirow{2}{*}{ Z-value } & \multirow{2}{*}{$\begin{array}{l}\text { Lower } \\
\text { Limit }\end{array}$} & \multirow{2}{*}{$\begin{array}{l}\text { Upper } \\
\text { Limit }\end{array}$} \\
\hline & & & & & \\
\hline \multicolumn{6}{|l|}{ Cusp } \\
\hline Intercept $(y)$ & -1.70 & 0.07 & $-25.89 * * *$ & -1.828 & -1.571 \\
\hline Sickness absenteeism $(y)$ & 1.01 & 0.05 & $20.91 * * *$ & 0.914 & 1.104 \\
\hline Intercept $(b)$ & 4.59 & 1.28 & $3.57 * * *$ & 2.071 & 7.116 \\
\hline Workload $(b)$ & -0.71 & 0.27 & $-2.60 *$ & -1.239 & -0.173 \\
\hline Team adaptability $(b)$ & -0.71 & 0.33 & $-2.17 * *$ & -1.354 & -0.068 \\
\hline Intercept $(a)$ & 2.46 & 0.79 & $3.09 * * *$ & 0.900 & 4.025 \\
\hline Task cohesion $(a)$ & -0.93 & 0.22 & $-4.13^{*}$ & -1.366 & -0.486 \\
\hline Model fit statistics & $R^{2}$ & AIC & $\mathrm{AICc}$ & $\mathrm{BIC}$ & \\
\hline Linear model & 0.073 & 626.766 & 627.003 & 644.550 & \\
\hline Logistic model & 0.168 & 600.865 & 601.198 & 622.206 & \\
\hline Cusp model & 0.377 & 617.644 & 618.090 & 642.542 & \\
\hline
\end{tabular}

$13.12(2)$,

$\chi^{2}$ difference test between the Linear model and the Cusp model $p=.001$

Note. ${ }^{*} p<0.05 ; * * p<0.01 ; * * * p<0.001$ (two-tailed). 


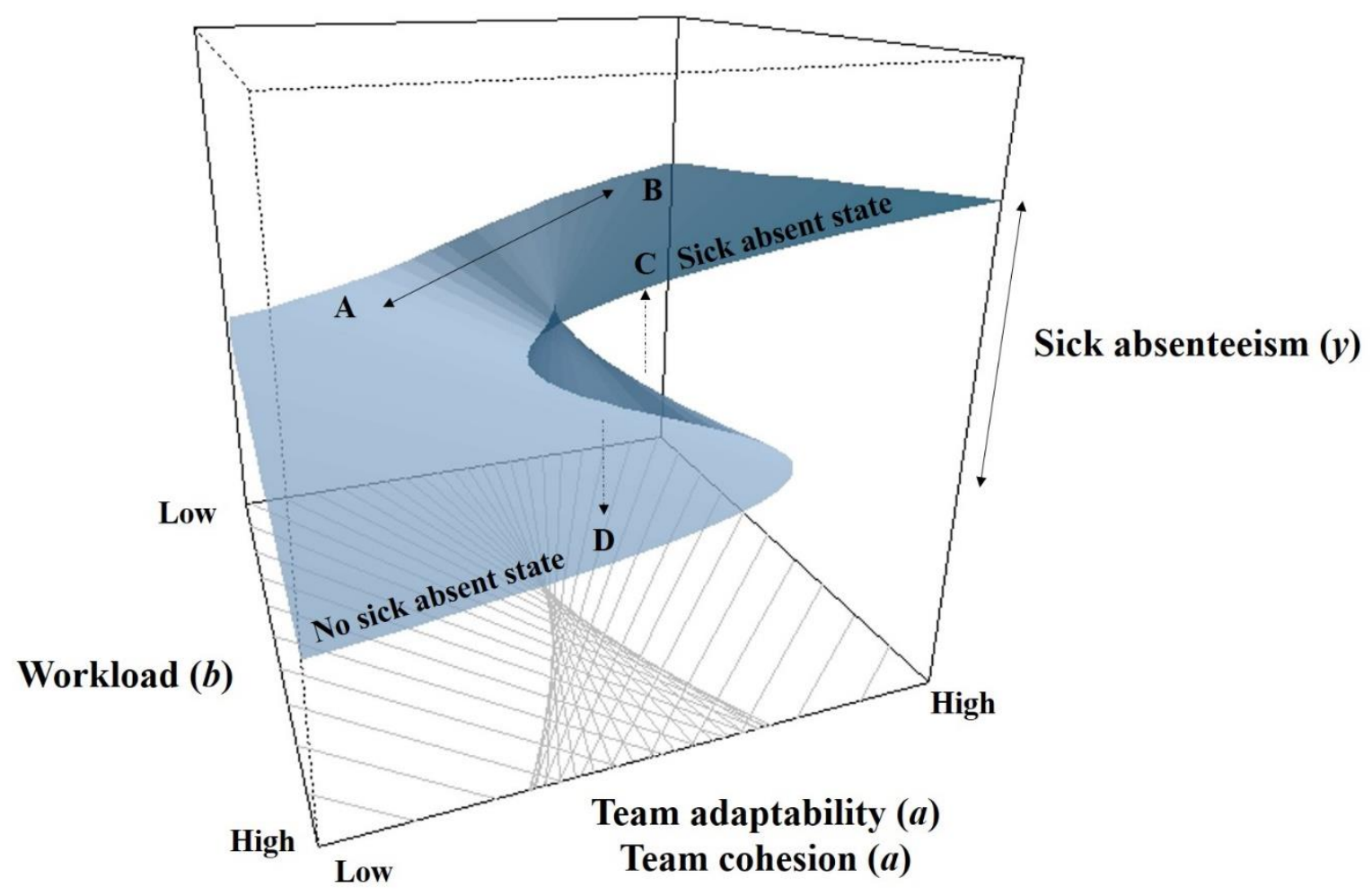

Figure 1. Cusp catastrophe model of sickness absenteeism, with workload as the bifurcation factor and team adaptability and team cohesion as the asymmetry factors. 


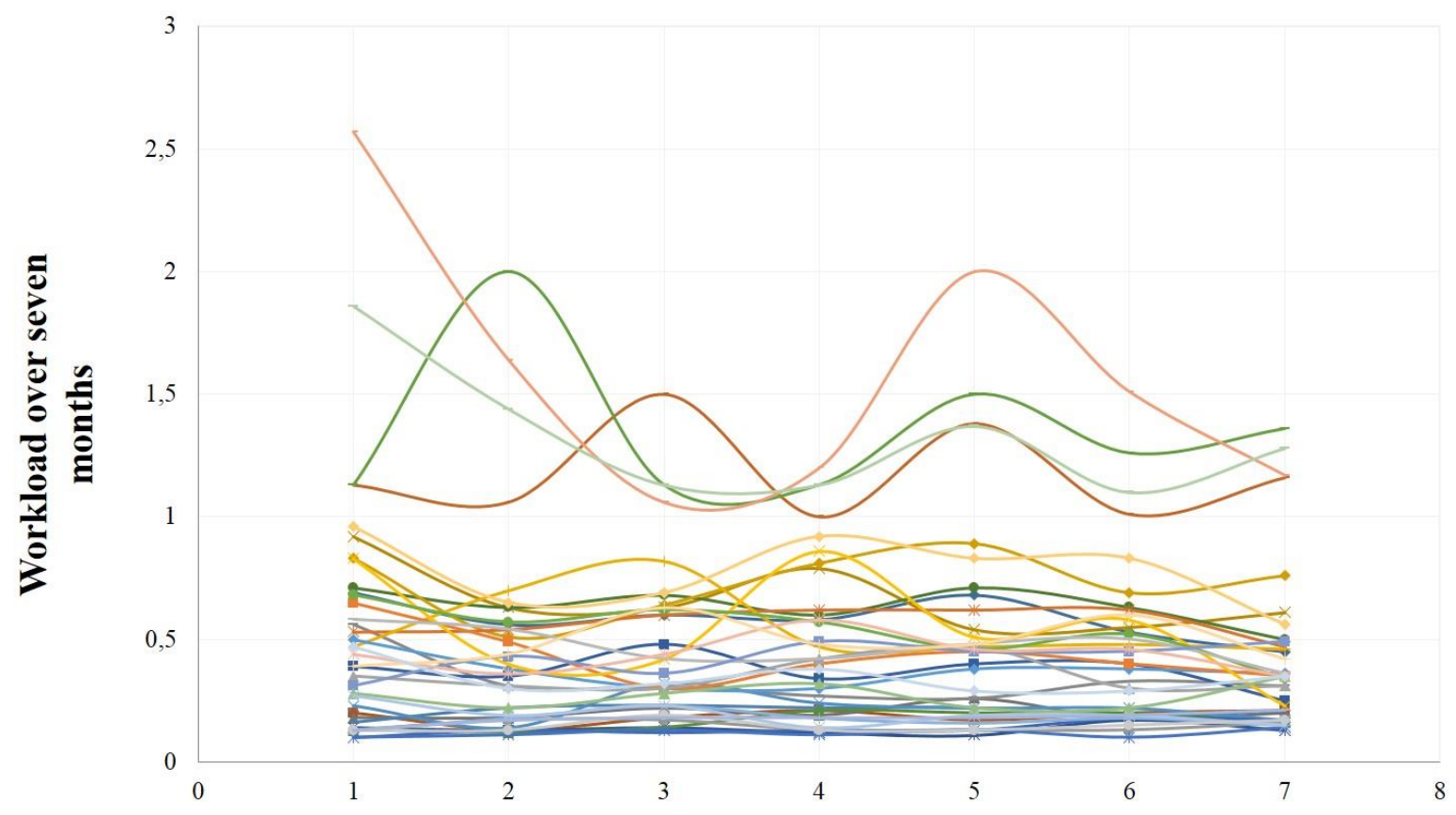

Figure 2. The within team trajectories of workload over seven months. 


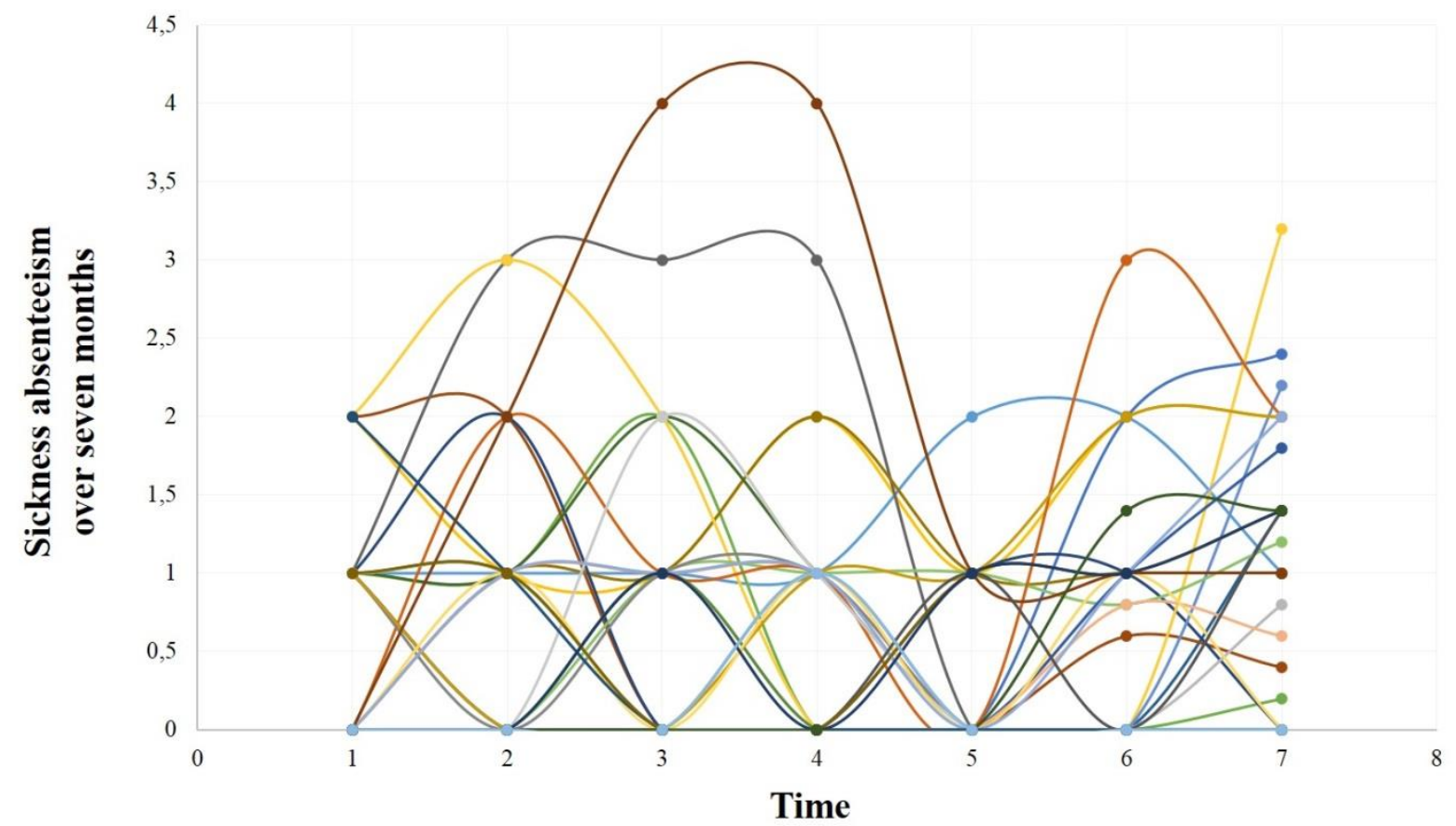

Figure 3. The within team trajectories of sickness absenteeism over seven months. 

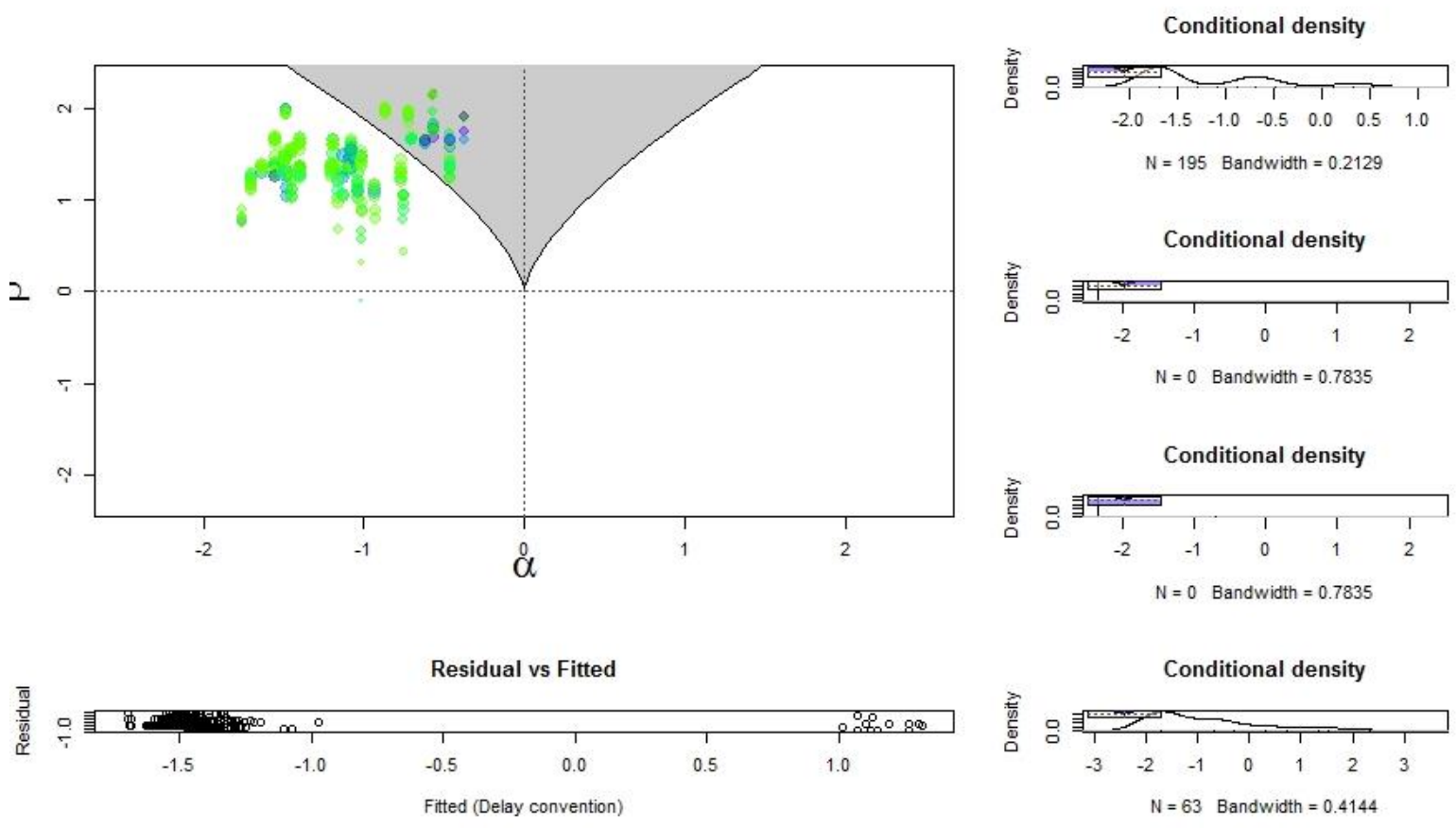

Figure 4. 2-Dimension cusp $p d f$ for sickness absenteeism using the Maximum Likelihood estimation. Coloured dots represent observed values of sickness absenteeism for each team over seven months. 


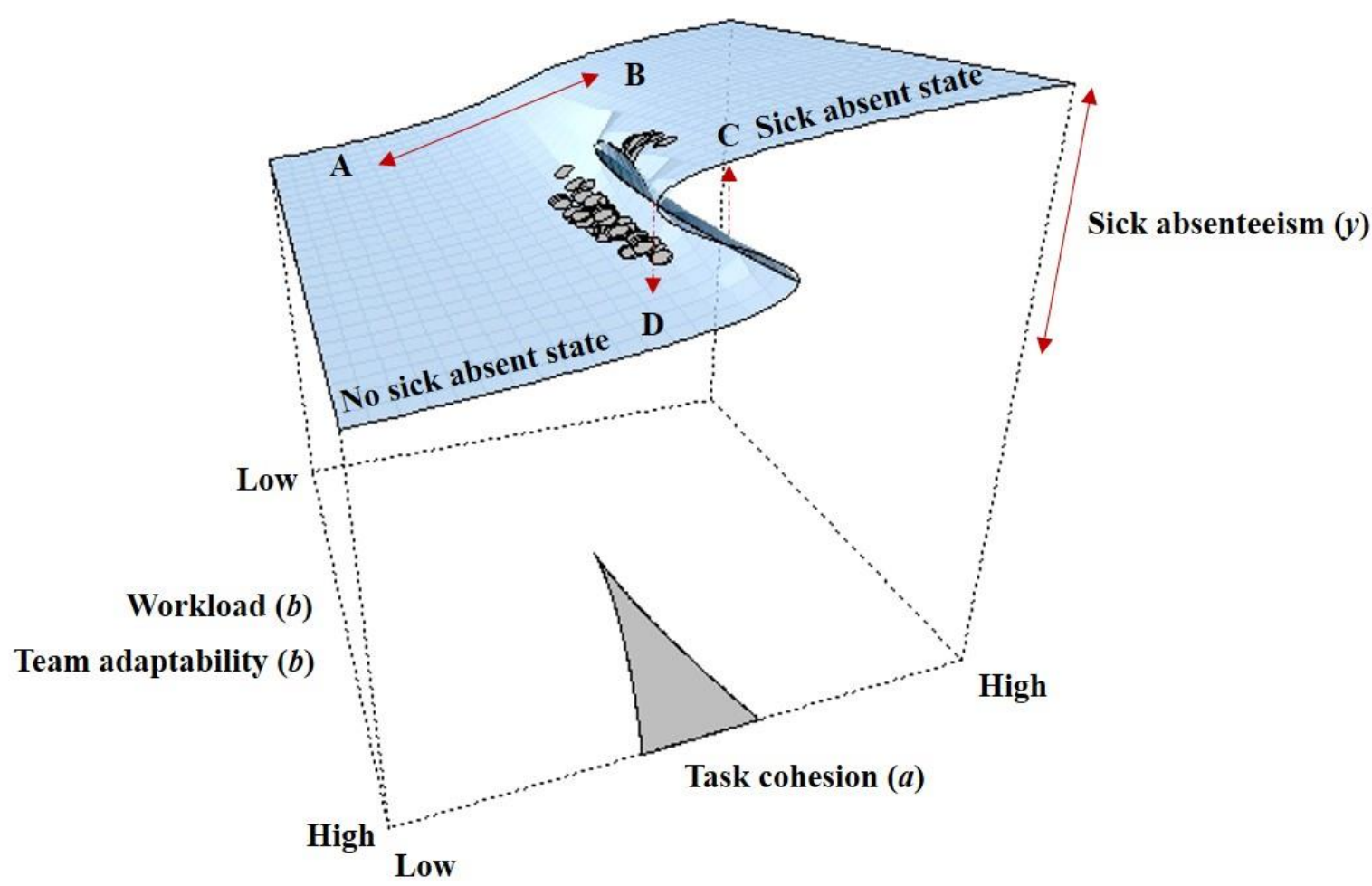

Figure 5. 3-Dimension cusp pdf for sickness absenteeism using the Maximum Likelihood estimation. Grey dots represent observed values of sickness absenteeism for each team over seven months. 